\title{
Functional Consequences of Neonatal Infraorbital Nerve Section in Rat Trigeminal Ganglion
}

\author{
Mark F. Jacquin, ${ }^{\star}$ William E. Renehan, ${ }^{\star}$ Bradley G. Klein, ${ }^{\star}$ Richard D. Mooney, $\dagger$ and Robert W. \\ Rhoades $\dagger$ \\ *Department of Neuroscience, New York College of Osteopathic Medicine, Old Westbury, New York 11568, and \\ †Department of Anatomy, University of Medicine and Dentistry of New Jersey, School of Osteopathic Medicine, \\ and Rutgers Medical School, Piscataway, New Jersey 08854
}

Standard single-unit recording and stimulation techniques were used to assess the topographic organization, receptive field properties, and projections of cells $(n=297)$ in the ophthalmicmaxillary part of the trigeminal ganglion in 6 normal adult rats and 15 adults with unilateral infraorbital nerve section at birth (cells recorded ipsilateral to lesion: $n=641$; cells recorded on the intact side: $n=223$ ). Stimulating electrodes were placed on the central portion of the regenerate infraorbital nerve and in the trigeminal brain stem subnucleus caudalis in 6 nerve-damaged rats and at equivalent points in 5 normal animals. Data from the normal rats and the intact side of the nerve-damaged animals were identical and were considered together. Of these cells, $73.5 \%$ had infraorbital receptive fields. Of these, $77.2 \%$ were discharged by vibrissa stimulation (43.8\% slow-adapt type I, $10.3 \%$ slow-adapt type II, $27.6 \%$ low-velocity sensitive rapid adapt, $16.8 \%$ high-velocity sensitive rapid adapt, and $1.5 \%$ noxious-biased), while the rest responded best to guard hair deflection $(12.0 \%)$, gentle skin indentation $(4.5 \%)$, or a strong pinch or deep pressure $(6.3 \%)$. In stereotaxically matched penetrations in ganglia ipsilateral to the neonatal infraorbital nerve lesions, only $40.6 \%$ of the cells had infraorbital receptive fields. Of these, only $37.7 \%$ responded to vibrissa stimulation $\mathbf{2 9 . 8 \%}$ slow-adapt type I, 1.2\% slow-adapt type II, $2.2 \%$ low-velocity sensitive rapid adapt, $32.9 \%$ high-velocity sensitive rapid adapt, $33.9 \%$ noxious). Other infraorbital cells responded best to guard hair deflection (11.9\%), gentle skin indentation $(10.8 \%)$, or a strong pinch or deep pressure (39.6\%). An additional 30 cells did not have a detectable receptive field and were identified only by infraorbital and brain-stem shocks. We also recorded cells with unusual infraorbital receptive fields: 9 units responded to more than 1 vibrissa, 4 were activated by both vibrissa and guard hair deflection, 10 had unusually large skin or deep receptive fields, 1 had a split receptive field, and 7 were discharged only by deep pressure to the region of the nerve section. Seven cells with infraorbital receptive fields were not driven by infraorbital shocks, and 2 were not activated by brain-stem shocks. In normal rats, all cells with infraorbital receptive fields were driven by both electrodes. The percentages of receptive field types for noninfraorbital cells were unchanged in ganglia ipsilateral to the damaged nerve. We conclude that a neonatal infraorbital lesion results in (1) a reduced number of cells with

\footnotetext{
Received Feb. 24, 1986; revised June 9, 1986; accepted June 10, 1986.

This work was supported in part by Grants DE07662, DE06528, EY03546, NS07240, NS07444, and BNS8515737; the UMDNJ Foundation; and the American Osteopathic Association. Invaluable technical assistance was provided by Ann Marie Szczepanik. Thanks to Dr. Gordon Macdonald for providing the animals used in this study.

Correspondence should be addressed to Dr. Mark F. Jacquin at the above address.

Copyright (C) 1986 Society for Neuroscience $0270-6474 / 86 / 123706-15 \$ 02.00 / 0$
}

infraorbital receptive fields, (2) a significantly higher percentage of infraorbital cells with noxious- or velocity-biased receptive fields; (3) cells that project into the infraorbital nerve without receptive fields; and (4) cells with unusual receptive fields.

Concerning the topographic organization of the ophthalmicmaxillary portion of the intact ganglion, cells with ophthalmic receptive fields were located dorsomedially. Mandibular units were encountered dorsolaterally. Maxillary units were recorded throughout the ophthalmic-maxillary part of the ganglion. Dorsal row vibrissae were represented medially, while ventral row vibrissae cells occurred laterally and ventromedially. Cells innervating rostral vibrissae tended to occupy ventral regions, while caudal vibrissae cells tended to be represented dorsally. Oral maxillary units were encountered ventrolaterally. In ganglia ipsilateral to a neonatal infraorbital lesion, topographic alterations were observed. Ophthalmic cells were more widely distributed, and rostral and caudal vibrissa afferents were distributed throughout the dorsoventral axis. Other topographic relationships appeared normal.

The trigeminal system has become a useful model for study of the factors responsible for the development of ordered connections in the mammalian CNS. Deafferentation procedures have been used extensively to show that peripheral connections play an important role in the development of brain maps, which ordinarily correspond in a point-to-point pattern with the periphery (e.g., Bates and Killackey, 1985; Belford and Killackey, 1980; Durham and Woolsey, 1984; Jacquin and Rhoades, 1983, 1985, 1986; Jeanmonod et al., 1981; Killackey et al., 1976, 1978; Simons et al., 1984; Van der Loos and Woolsey, 1973; Waite and Cragg, 1979; Weller and Johnson, 1975; Woolsey and Wann, 1976; Woolsey et al., 1979). Experimentally induced variations in the innervation of the mystacial vibrissae have been shown to produce transynaptic alterations during a critical period of postnatal development in the rat. Though such anatomical studies are now numerous, little is known regarding the functional consequences of trigeminal deafferentation (see Simons et al., 1984 , for a review), especially with respect to the neurons that are directly perturbed, namely, the trigeminal primary afferents. In the present study, we have attempted to fill this void.

Previous studies have shown that infraorbital nerve section at birth profoundly alters the structural organization of the infraorbital nerve and trigeminal ganglion. This manipulation reduces the number and average diameter of axons in the vibrissal components of the infraorbital nerve distal to the point of transection (Waite and Cragg, 1982; B. G. Klein, W. E. Renehan, M. F. Jacquin, and R. W. Rhoades, unpublished observations), reduces the number of myelinated and unmyelinated axons in the infraorbital nerve proximal to the point of transection (Mooney et al., 1983), reduces the number of ganglion cells giving 
rise to the infraorbital nerve (Jacquin and Rhoades, 1983; Klein et al., unpublished observations), and markedly alters the topographic representation of the mystacial vibrissae in the ophthalmic-maxillary portion of the ganglion (Erzurumlu and Killackey, 1983; Math et al., 1984; Rhoades et al., 1983a). The effects of neonatal infraorbital nerve section or vibrissa follicle cauterization have also been assessed with electrophysiological techniques in the brain stem (Waite, 1984; Waite and Cragg, 1982), thalamus (Verley and Onnen, 1981), and somatosensory cortex (Killackey et al., 1978; Pidoux et al., 1979; Simons et al., 1984; Waite and Cragg, 1982; Waite and Taylor, 1978; Welt, 1977). Neurons with altered response properties have been encountered in all of these regions. Such changes could arise from (1) changes in the receptive fields of trigeminal ganglion cells that are passed on, without further change, to the remainder of the trigeminal neuraxis; (2) altered primary afferent terminal arborization patterns in the brain stem; (3) reorganization of postsynaptic central connections; or (4) some combination of these events.

As a first step in determining which of the above factor(s) are responsible for lesion-induced functional reorganization in the trigeminal system, we have carried out an extracellular singleunit recording study in the trigeminal ganglion. Portions of this study have been presented in abbreviated form (Renehan et al., 1985).

\section{Materials and Methods}

A total of 22 adult Wistar rats of both sexes provided data. Of these, 16 were subjected to left infraorbital nerve section within $12 \mathrm{hr}$ after birth using a previously described procedure (Jacquin and Rhoades, 1983, 1985). No attempt was made to prevent regeneration. Animals were then used in recording experiments no less than $60 \mathrm{~d}$ later. Recordings were made in 16 ganglia ipsilateral to neonatal transection. In 7 of these animals, data were collected from both sides. Six animals were normal. Experiments were carried out with full knowledge of the animal's experimental status.

Rats were anesthetized with Nembutal $(60 \mathrm{mg} / \mathrm{kg}$, i.p., $n=18)$ or urethane $(1.2 \mathrm{gm} / \mathrm{kg}$, i.p., $n=4)$ and administered atropine sulfate (1$2 \mathrm{mg}$, i.p.). Supplemental doses of anesthetic were delivered periodically to maintain a deep level of anesthesia, as determined by continuous monitoring of heart rate. Animals were tracheostomized, secured in a stereotaxic headholder which provided access to all trigeminal fields, immobilized with gallamine triethiodide $(35 \mathrm{mg} / \mathrm{kg}$, i.p., supplemented hourly), and artificially respirated (70 strokes $/ \mathrm{min}, 3.5-5.0 \mathrm{~cm}^{2}$ tidal volume). Heart rate was continuously monitored and body temperature was maintained at $36-38^{\circ} \mathrm{C}$ with a thermostatically controlled heating pad. In experiments where the forebrain was aspirated, $10 \%$ dextran was also administered (approx. $1 \mathrm{~cm}^{3}$ every $2 \mathrm{hr}$, i.p.).

Two experimental strategies were employed for recording single units in trigeminal ganglia:

1. Tungsten microelectrodes ( $n=11$ rats: 10 ganglia ipsilateral to nerve section and 7 intact ganglia). Portions of the dorsal calvarium were drilled away bilaterally, and a tungsten microelectrode (Frederick Haer, resistance $=12-20 \mathrm{M} \Omega$ measured at $1 \mathrm{kHz}$ ) was stereotaxically positioned on the cortical surface and aimed at the trigeminal ganglion. The bregma and the midline suture served as reference points. The electrode was manually lowered $8.0 \mathrm{~mm}$. A Kopf stepping micromanipulator provided further descent until the dura overlying the trigeminal ganglion was penetrated, as determined by the sudden appearance of multiple unit activity in response to continual stroking of the rat's face. Single units were amplified, displayed, and monitored using standard methods (e.g., Rhoades et al., 1983b). Somatosensory stimulation was delivered using previously described methods (Jacquin et al., 1986), and receptive fields were plotted on detailed drawings of the rat head. Afferent receptor type was categorized according to criteria established by Gottschaldt et al. (1973) for vibrissa afferents, and Burgess and Perl (1973) and Brown and Iggo (1967) for non-vibrissa-related units. For vibrissa afferents, particular care was taken to determine the number and location of vibrissae that, when deflected, discharged the unit. Sensitivity to vibration and to the direction, velocity, and magnitude of displacement were assessed, as was the sustained vs transient nature of
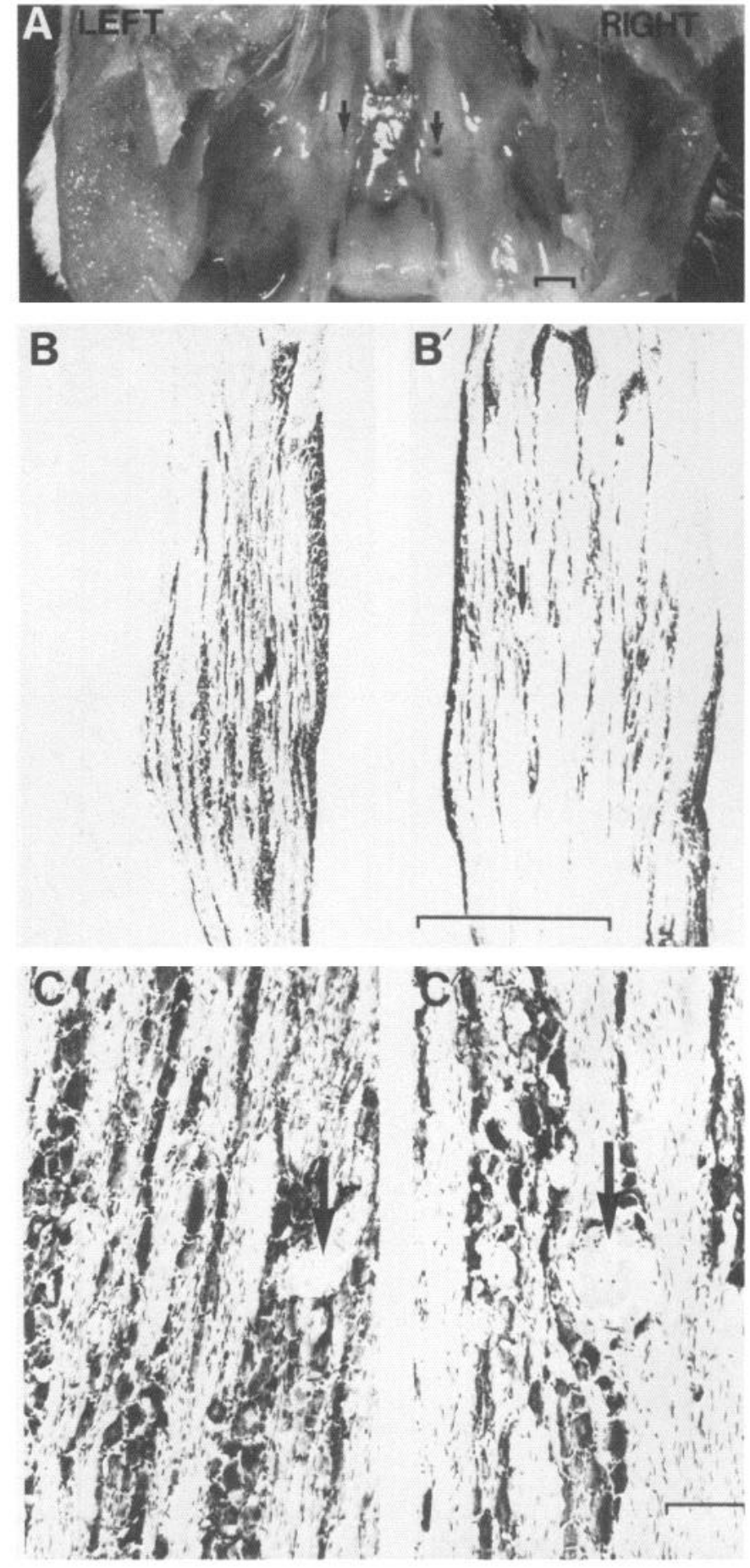

Figure 1. Photomicrographs illustrating the region of the adult trigeminal ganglion sampled in a typical recording session using tungsten microelectrodes. A, Arrows highlight blood spots that mark the point of entry of electrode tracks through the ophthalmic-maxillary portion of trigeminal ganglia ipsilateral (left) and contralateral (right) to a neonatal infraorbital nerve section (case 5-30). Photograph taken in situ after removal of the brain. Rostral is up in the figure. Nissl-stained, $35-\mu \mathrm{m}$ thick, horizontal sections through the 2 ganglia presented in $A$ are shown at low and high magnifications in $B$ and $C$, respectively. $B$ and $C$ were taken from the left ganglion; $B^{\prime}$ and $C^{\prime}$ from the right ganglion. Arrows depict the regions traversed by a tungsten electrode. Calibration bars: $A$ and $B, 1 \mathrm{~mm} ; C, 100 \mu \mathrm{m}$. 

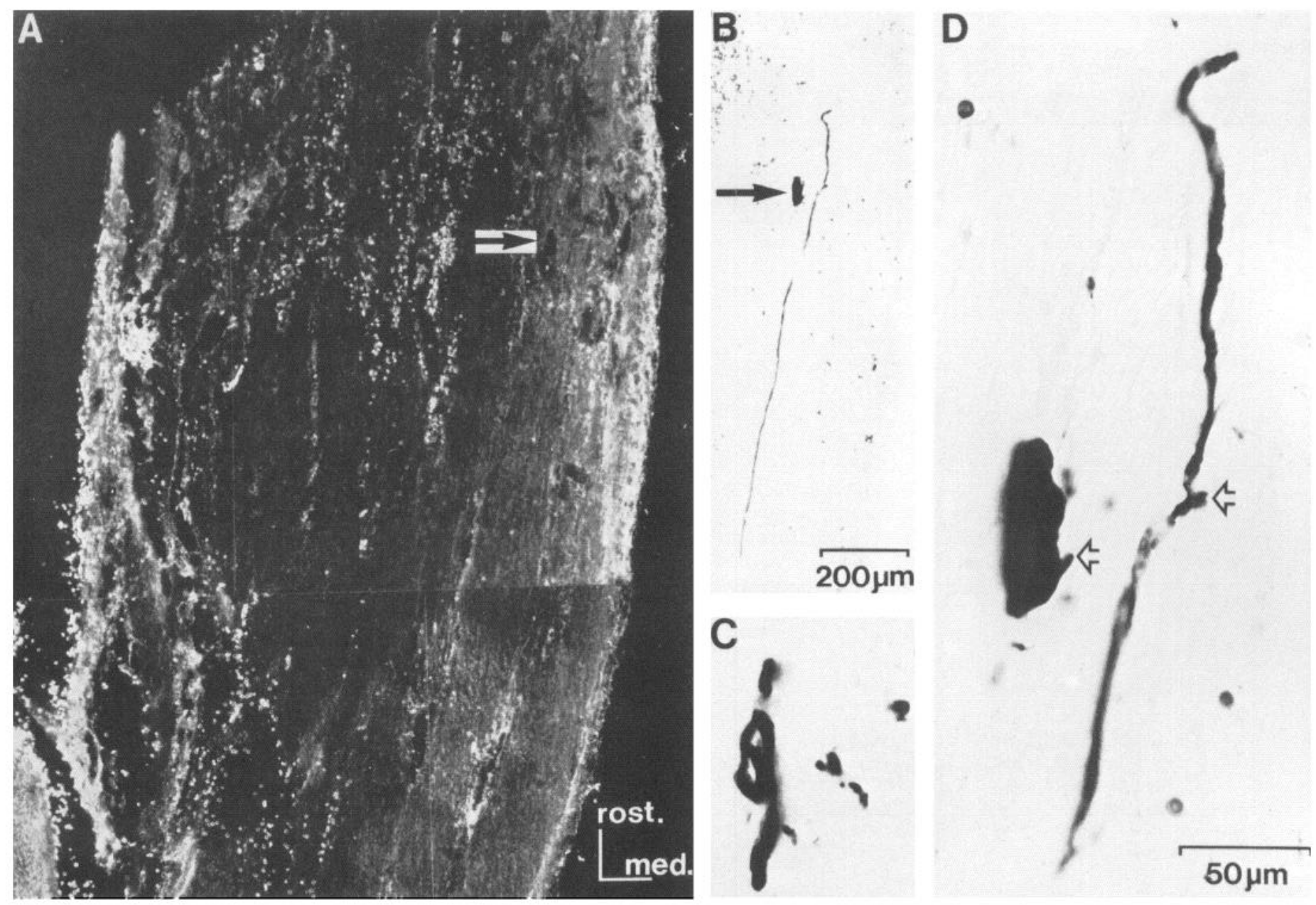

Figure 2. A, Dark-field photomicrograph of a horizontal section through the trigeminal ganglion showing the location (arrow) of a physiologically characterized and intracellularly labeled neuron in the ventromedial ophthalmic-maxillary region. See text for its response properties. HRP reaction product was visualized with diaminobenzidine. $B$, Same section at the same magnification under bright-field optics. Arrows are placed at equivalent points in the 2 micrographs for comparison. A portion of the axon can be seen coursing rostrocaudally in approximately the same mediolateral and dorsoventral planes as that of the cell body. $C$, The initial axon segment and its tortuous trajectory in an adjacent section. $D$, The soma, point of axon origin (left arrow), and point of axon bifurcation (right arrow) at higher magnification. Calibration in $D$ applies to $C$ as well.

the response to stimulation. Each unit's discharge in the absence of overt stimuli (spontaneous activity) was also noted.

An entire battery of somatosensory stimulation was delivered every $50 \mu \mathrm{m}$ of descent through the ganglion. All well-isolated cells were categorized and their depth within the ganglion noted. A given electrode track was terminated when the electrode hit petrous bone. The electrode was then retracted and repositioned 0.3 or $0.5 \mathrm{~mm}$ lateral or medial to this site and another track was initiated. In most experiments, an entire mediolateral comb of penetrations was carried out at a given distance caudal to the bregma. The rostrocaudal positioning of the electrode was not altered within an experiment but varied between 1.0 and $3.0 \mathrm{~mm}$ caudal to the bregma between experiments.

At the end of the recording session, the rat was given a lethal dose of Nembutal and perfused transcardially with $0.9 \%$ saline followed by $10 \%$ neutral buffered formalin. Photographs were taken of ganglia in situ, with blood spots marking the approximate point of penetration. The ganglia were then removed, sectioned horizontally on a cryostat at 35 $\mu \mathrm{m}$, and stained with cresyl violet. Electrode tracks were readily reconstructed via bloodstains or tissue necrosis.

Tungsten recording experiments permitted recording from a large number of ganglion cells, providing information on their topography and functional modality. However, this technique did not allow for detection of antidromic activation of these cells, given the large shock artifacts necessitated by the amplification required and the short latencies of the responses to infraorbital nerve and brain-stem shocks. Recording with relatively large-tipped tungsten microelectrodes also cre- ated the possibility of a sample bias toward larger ganglion cells. To combat these problems, we also employed a second experimental approach.

2. Glass microelectrodes $(n=11$ rats: 6 ganglia ipsilateral to nerve section and 5 normal ganglia). The left dorsal calvarium was drilled away and the entire forebrain was aspirated, exposing the left trigeminal ganglion. The overlying dura was carefully incised and deflected, and the ganglion was kept moist in warm mineral oil. A concentric bipolar stimulating electrode $(0.5 \mathrm{~mm}$ intertip distance) was positioned on the left infraorbital nerve at the level of the anterior superior alveolar foramen by laterally retracting the orbital contents (Jacquin et al., 1984). This stimulation site was therefore proximal to the point of neonatal transection. Another stimulating electrode was inserted into the rostral half of the left trigeminal brain stem subnucleus caudalis via a previously described surgical approach (Jacquin et al., 1986). Both the infraorbital nerve and the medulla were bathed in warm mineral oil.

Ganglion cells were recorded with glass (Microstar) microelectrodes, filled with $3.0 \mathrm{M} \mathrm{KCl}(\mathrm{pH} \mathrm{7.6,Z}=10-30 \mathrm{M} \Omega$ ). An electrode was positioned on the surface of the ganglion under visual control, and $3 \%$ agar in saline was liberally applied to the operative area to minimize movements. Unit discharges were amplified by a high-input-impedance preamplifier (Eutectics, model 400A). Search stimuli from the infraorbital nerve or TrV stimulating electrodes consisted of monophasic, 50 $\mu \mathrm{sec}$, rectangular 20-30 V pulses delivered at a rate of $1 \mathrm{~Hz}$. The recording electrode was advanced in $3 \mu \mathrm{m}$ steps. Receptive fields and afferent receptor type were categorized as described above. Threshold 
CASE: 5-31

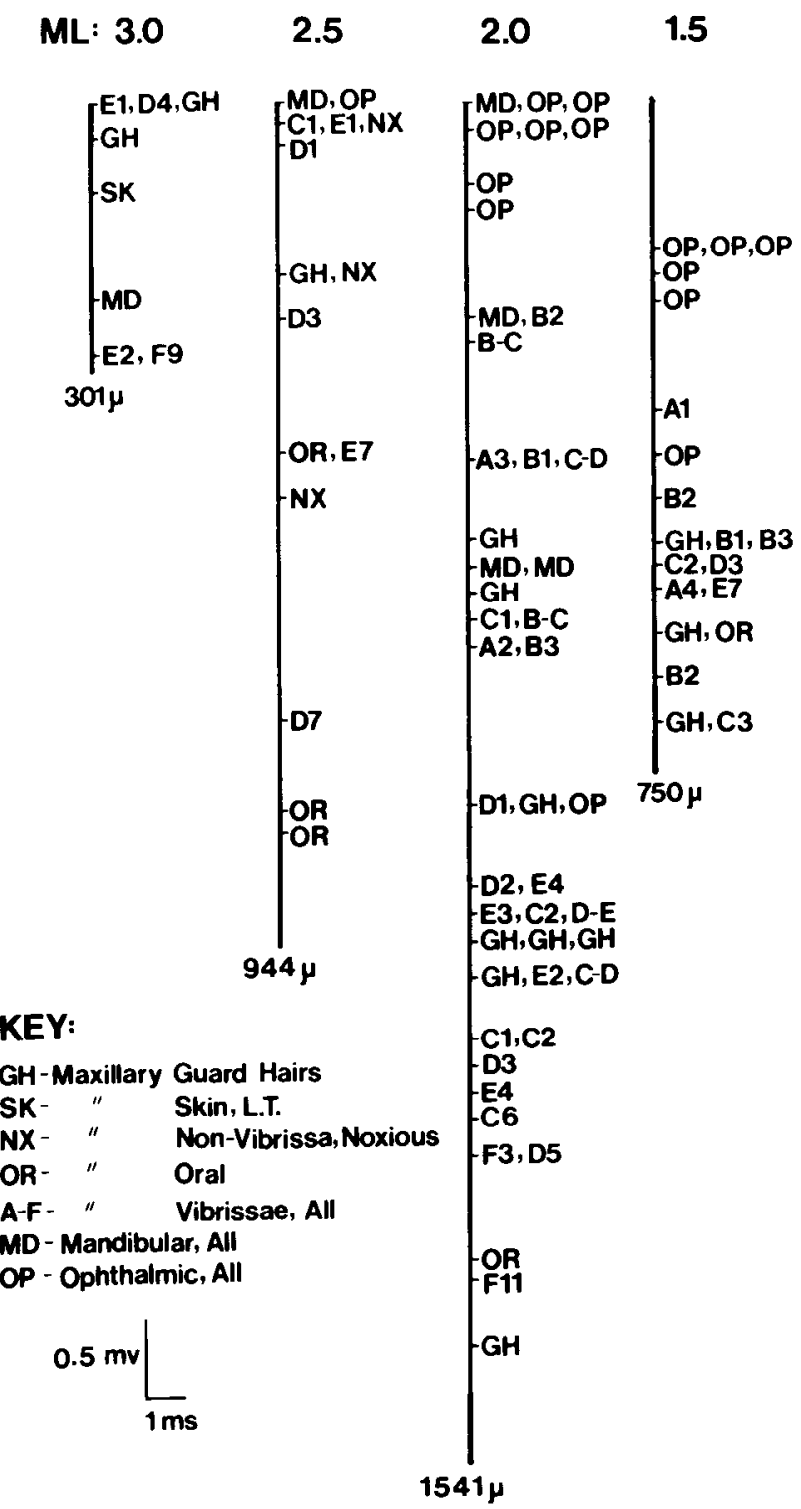

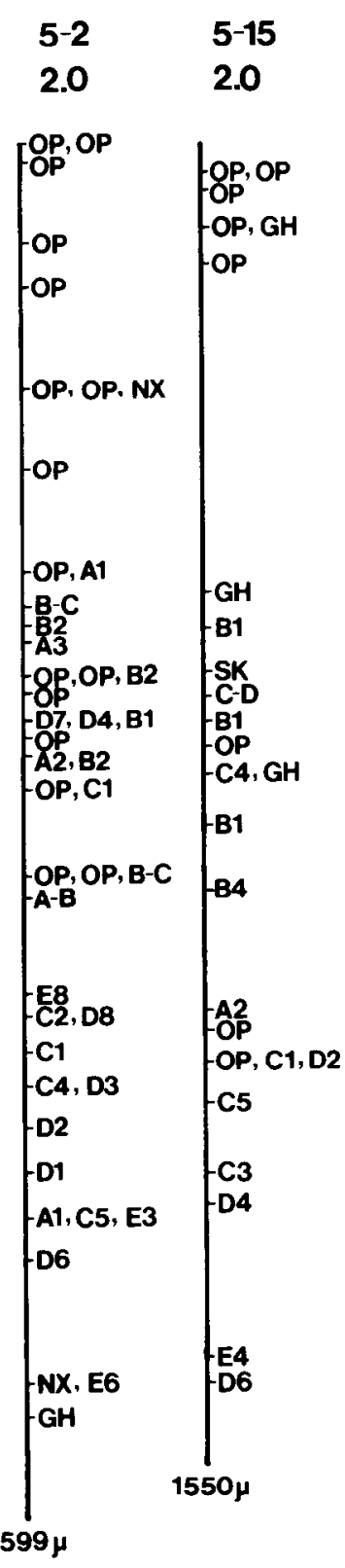

5-30

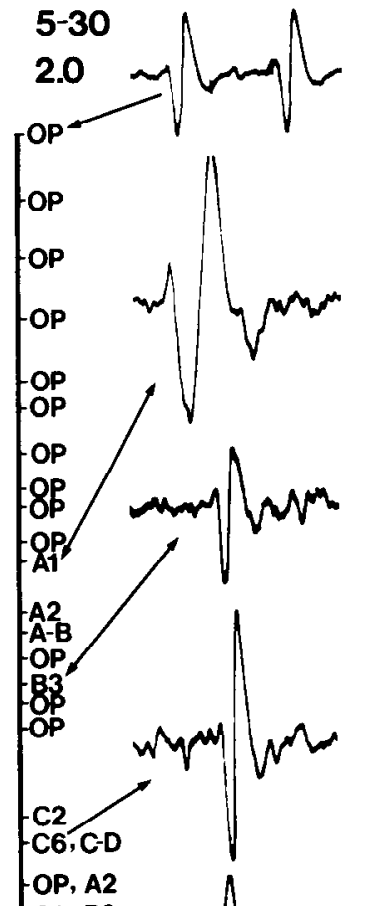

-C3, D2
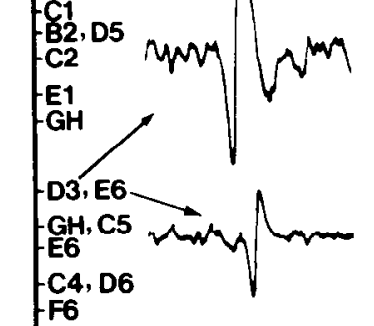

F

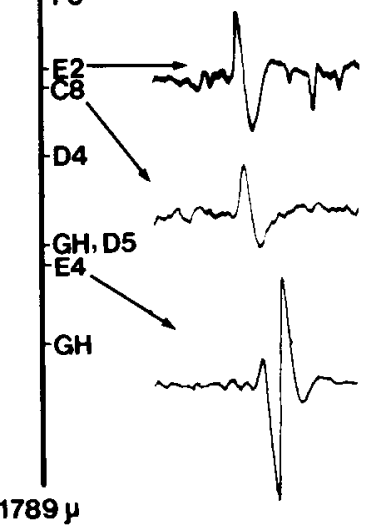

Figure 3. Receptive fields of each unit isolated with tungsten microelectrodes in 7 penetrations through 4 adult trigeminal ganglia contralateral to neonatal infraorbital nerve transection. Electrodes were positioned 1-3 mm caudal to the bregma and at varying distances from the midline suture $(M L$, in $\mathrm{mm})$. Each unit's depth in the ganglion is scaled at the point that provided the largest action potential. Commas separate receptive fields of more than 1 unit isolated at a given depth. Overall track depth is indicated at the bottom of each reconstruction. As shown in the Key, mandibular and ophthalmic fields are noted as such, while maxillary fields have been partitioned by receptor organ. For maxillary vibrissae fields, the nomenclature of Zucker and Welker (1969) has been used: A is the most dorsal row of vibrissae; F, the most ventral; numbers following the row designation denote relative rostrocaudal position (low-numbered vibrissae are caudal to higher-numbered vibrissae); the caudalmost maxillary vibrissae "straddle" rows and are hyphenated without numbers. Representative oscillographs are shown on the right for selected units isolated in the electrode track reconstructed on the far right. Responses were evoked by peripheral stimulation; their calibration is shown in the key.

and latency for antidromic activation from infraorbital and TrV stimulating electrodes were also noted. Multiple penctrations were carried out as described above.

An experiment was terminated when an entire mediolateral comb of electrode tracks was achieved at a given rostrocaudal level. Given that electrode placements were made under visual control, it was not nec- essary to verify recording sites routinely. In a few of these experiments, however, HRP was ejected into the last recorded cell at the completion of the last track from an electrode containing 6\% HRP in $0.05 \mathrm{M}$ Tris and $0.3 \mathrm{M} \mathrm{KCl}$. Parameters for HRP ejection and diaminobenzidine visualization of HRP reaction product were as described previously (Jacquin et al., 1986). 

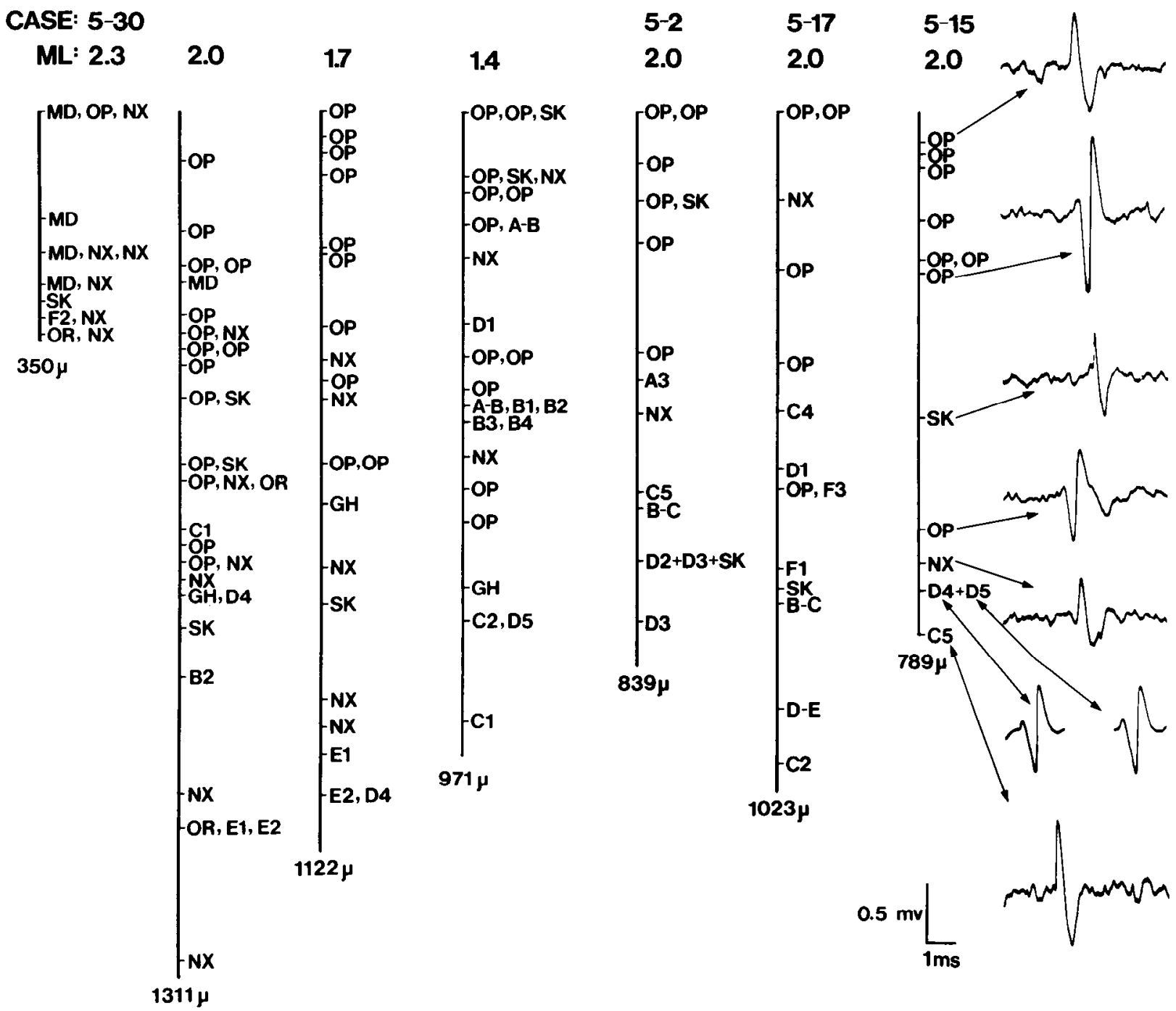

Figure 4. Receptive fields of each unit isolated with tungsten microelectrodes in 7 penetrations through 4 adult trigeminal ganglia ipsilateral to neonatal infraorbital nerve section (compare with Fig. 3). Note that cases 5-30, 5-2, and 5-15 each provided data from ganglia ipsi- and contralateral to the lesion. Representative oscillographs are shown at right for arrow-designated units. All conventions as in Figure 3 , except that a plus sign indicates that 1 unit responded to more than 1 receptor organ.

\section{Results}

\section{Verification of recording sites}

Figure 1 illustrates the locations of tungsten electrode tracks through trigeminal ganglia ipsilateral (Fig. 1, $A, B, C$ ) and contralateral (Fig. 1, $A, B^{\prime}, C^{\prime}$ ) to a neonatal infraorbital nerve transection. Arrows indicate the point of entry into both the left and right ganglia (Fig. $1 A$ ) and the regions through which extracellular recordings were obtained in Nissl-stained horizontal sections (Fig. 1, B, C). Note that the electrodes passed through cell-rich portions of the ophthalmic-maxillary portion of the ganglion and that the left ganglion was much narrower than its normal right counterpart. Also note the presence of large and small ganglion cells in both the left and right ganglia (Fig. 1, C, $C^{\prime}$, respectively).

The morphology of an HRP-labeled ganglion cell is illustrated in Figure 2. It is 1 of 5 cells we recovered following injection of HRP into the last cell recorded in an experiment. The cell was encountered $926 \mu \mathrm{m}$ ventral to the surface of the ganglion, $2.9 \mu \mathrm{m}$ caudal to the bregma, and $2.1 \mu \mathrm{m}$ lateral to the midline. It responded in a slowly adapting type I fashion to rostral de- flection of the B3 vibrissa. As can be seen in the dark-field micrograph in Figure $2 A$, the labeled cell body (arrow) and axon were recovered in the medial portion of the ganglion (also see corresponding bright-field micrograph in Fig. $2 B$ ). Both the soma and axon are shown at higher magnification in Figure 2, $C$ and $D$. Though the initial axon segment (left arrow in Fig. $2 D$ ) took an extremely tortuous course (Fig. $2 C$, an adjacent section) prior to its bifurcation (right arrow in Fig. $2 D$ ), the trajectory of the axon did not deviate far from the location of the cell body in either the mediolateral or dorsoventral planes. This spatial relationship between soma and axon in these 2 dimensions was typical of all of our recovered cells. This is important because it suggests that somal and axonal topography are similar in the mediolateral and dorsoventral axes of the trigeminal ganglion. Therefore, valid statements may be made about ganglionic topography based upon either somal or axonal recordings.

\section{Sample}

A total of 1161 units was recorded. In normal animals $(n=297$ units), or the intact side of lesioned cases ( $n=223$ units), 28 penetrations ( 14 with tungsten, 14 with glass electrodes) yielded 5 or more isolated units. On the average, a unit was encountered 


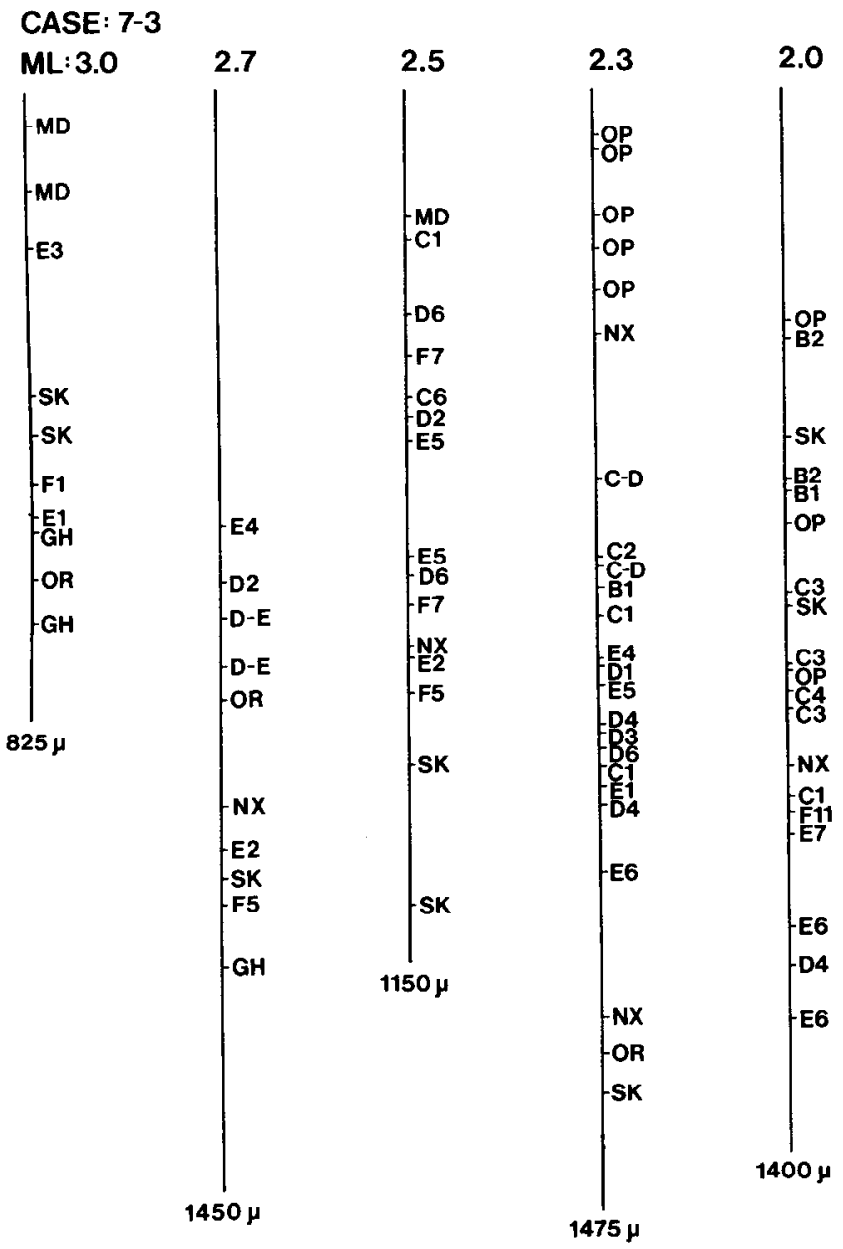

Figure 5. Receptive fields of each unit isolated with glass microelectrodes in 5 penetrations spanning the entire mediolateral extent of 1 adult trigeminal ganglion contralateral to neonatal infraorbital nerve section. In each track, the electrode was positioned $3.0 \mathrm{~mm}$ caudal to the bregma. All conventions as in Figure 3.

every $45.9 \mu \mathrm{m}$ using tungsten electrodes and every $89.1 \mu \mathrm{m}$ using glass electrodes (combined average encounter rate: 1 unit/ $62.3 \mu \mathrm{m}$ ). The average track depth was $1157.5 \mu \mathrm{m}$.

In ganglia ipsilateral to infraorbital transection ( $n=641$ units), 57 penetrations (33 with tungsten, 24 with glass electrodes) yielded 5 or more isolated units. On the average, a unit was encountered every $51.9 \mu \mathrm{m}$ using tungsten electrodes and every $81.6 \mu \mathrm{m}$ using glass electrodes (combined average encounter rate: 1 unit $/ 63.4 \mu \mathrm{m}$ ). The average track depth was $713.5 \mu \mathrm{m}$. Therefore, the encounter rate was similar for lesioned and normal cases; however, fewer units were isolated per track in lesioned subjects, due to shrinkage of the ganglion in the dorsoventral dimension. Glass electrodes also isolated fewer cells than tungsten electrodes in both normal and lesioned subjects.

An examination of Figures 3-6 indicates that tungsten and glass electrodes isolated a similar range of unit types. With respect to those units with maxillary receptive fields, guard hair, hairy skin, vibrissae, oral (mucosa and tooth-related), and nociceptive afferents were heavily sampled.

\section{Ganglionic topography}

Figures 3-6 also illustrate the somatotopic organization within the ganglion for both normal and infraorbital nerve-sectioned subjects. Representative penetrations are shown for intact ganglia using either tungsten (Fig. 3) or glass (Fig. 5) electrodes, and

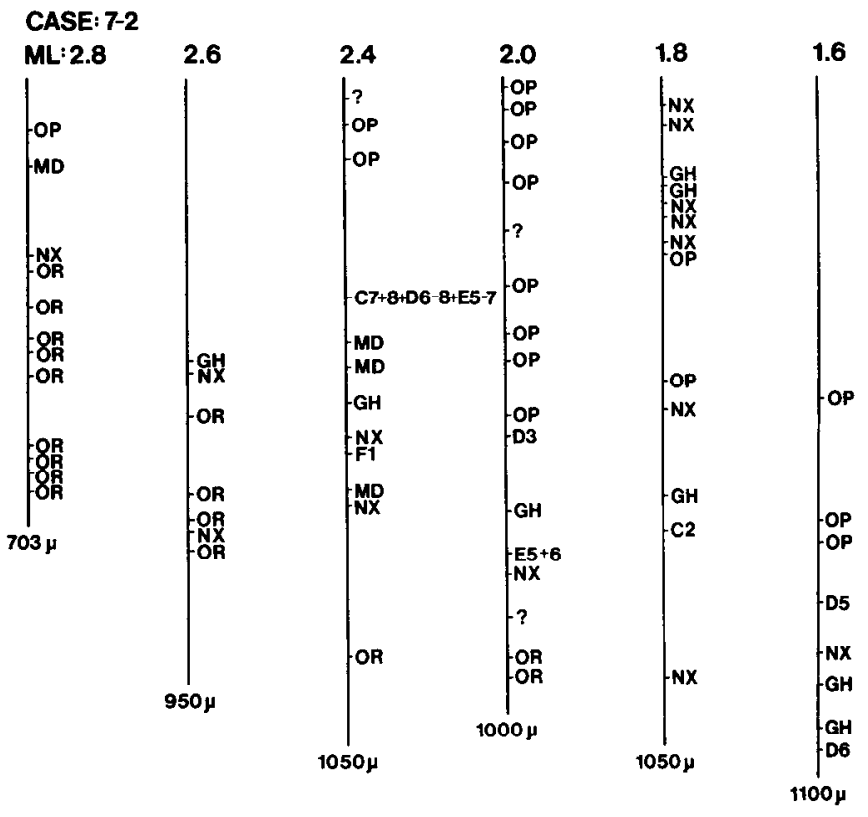

Figure 6. Receptive fields of each unit isolated with glass microelectrodes in 6 penetrations spanning the entire mediolateral extent of 1 adult trigeminal ganglion ipsilateral to neonatal infraorbital nerve section (compare with Fig. 5). In each track, the electrode was positioned $3.0 \mathrm{~mm}$ caudal to the bregma. All conventions as in Figure 3, except that "?" indicates an isolated unit without a discernible receptive field.

for ganglia ipsilateral to a neonatal infraorbital lesion using either tungsten (Fig. 4) or glass (Fig. 6) electrodes.

\section{Normal side}

A careful inspection of Figures 3 and 5 suggests the following generalizations concerning the topographic organization of the ophthalmic-maxillary portion of the intact ganglion:

1. Units with ophthalmic receptive fields were most heavily represented medially and were not recorded in penetrations through the most lateral portions of the ganglion (e.g., ML:3.0 in both Figs. 3 and 5). With rare exceptions, they were encountered only in the ganglion's dorsal half.

2. Units with mandibular fields were most heavily represented laterally and, with rare exceptions, were encountered only dorsally. Though not illustrated, our entire sample of mandibular units in this portion of the ganglion had receptive fields on the caudal portion of the face (i.e., from the corner of the mouth hack to the ear), regions normally innervated by the auriculotemporal and mylohyoid branches of the mandibular nerve. Lower lip, chin, and intraoral mandibular fields were not represented in this portion of the ganglion.

3. Units with maxillary fields were ubiquitous throughout the ophthalmic-maxillary portion of the ganglion, though they were less frequently encountered dorsally. Dorsally, they overlapped extensively with mandibular and ophthalmic units.

4. An intradivisional topography was evident for maxillary units. Cells innervating the dorsal $\mathrm{A}$ and $\mathrm{B}$ row vibrissae were recorded only in the medial ganglion, while the ventral $D, E$, and $F$ row vibrissae and intraoral structures were most heavily represented in the lateral ganglion. $C$ row vibrissae were largely interposed. The exception to this orderly replication of the dorsoventral maxillary field in the mediolateral plane of the ganglion was the reliable representation of largely rostral $\mathrm{C}-\mathrm{F}$ row vibrissae in the ventromedial ganglion. Thus, $\mathrm{C}-\mathrm{F}$ row vibrissae are innervated by cells in 3 of 4 transverse quadrants, the exception being the dorsomedial quadrant, which contains the $A$ and $B$ row vibrissal afferents. 


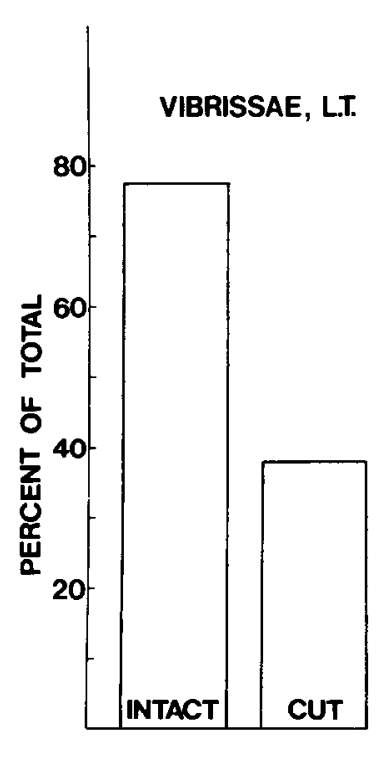

\section{ALL INFRAORBITAL UNITS}

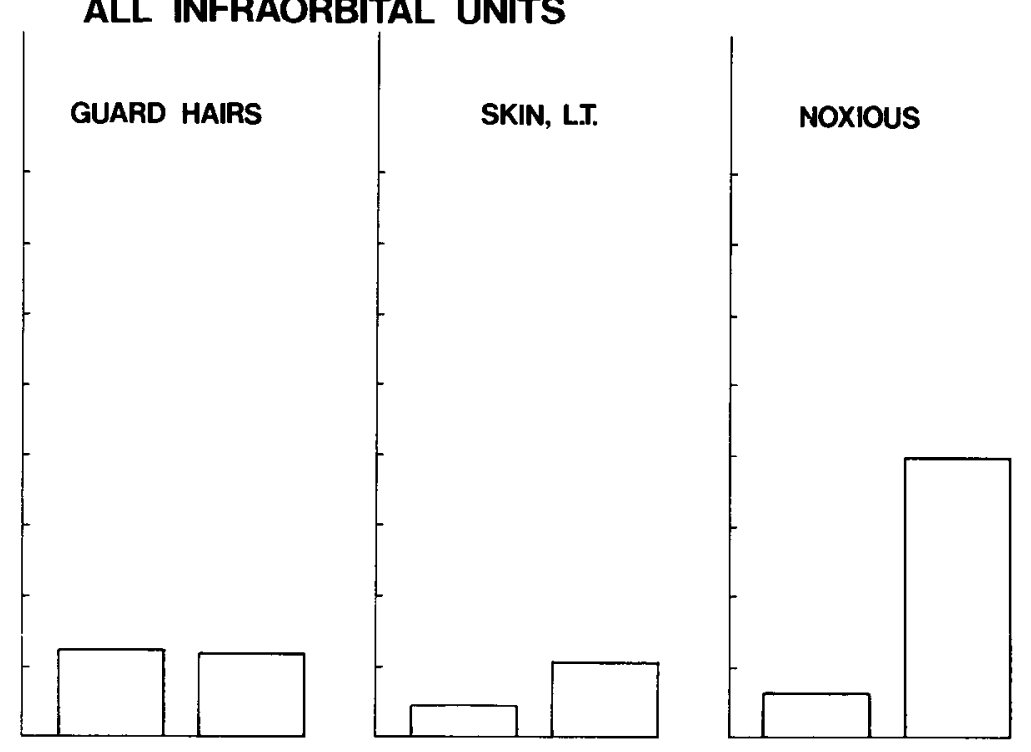

\section{ALL INFRAORBITAL VIBRISSAE UNITS}
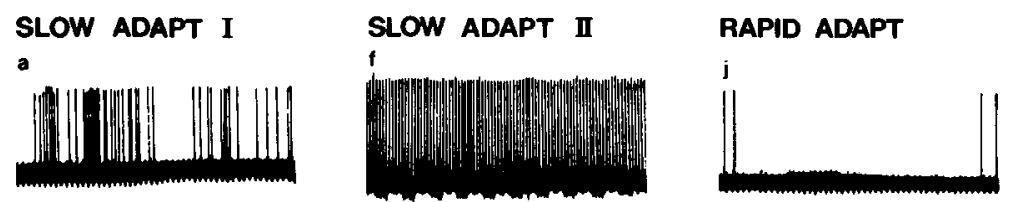

VELOCITY

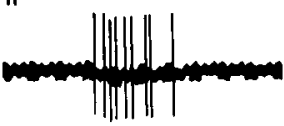

o
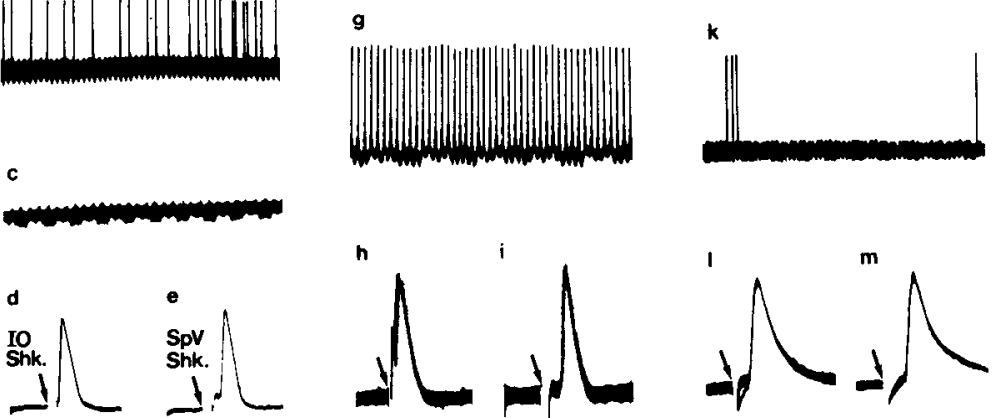

n
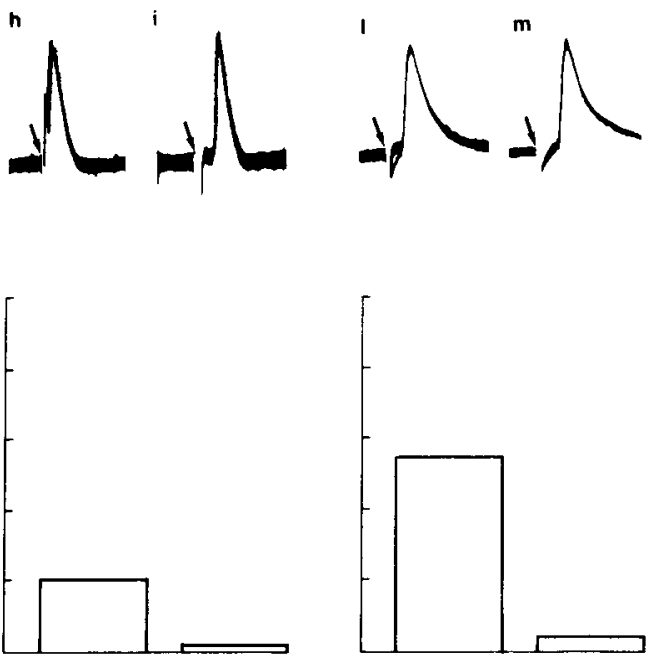

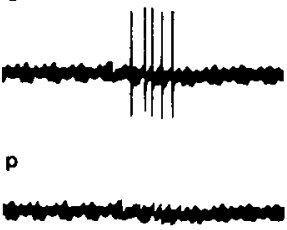

$\mathbf{q}$
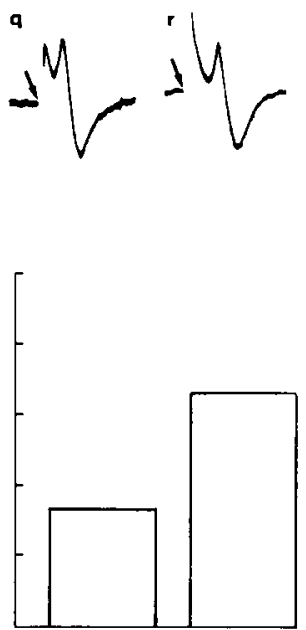

Noxious

$\mathbf{s}$
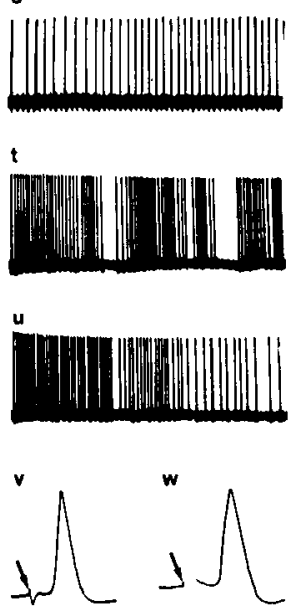

$10 \mathrm{mv}$

$.2 \sec (f, t, u)$

.1 sec(a-c,g, $, k, s)$

$50 \mathrm{~ms}(\mathrm{n}-\mathrm{p})$

$1 \mathrm{~ms}$ (all others)

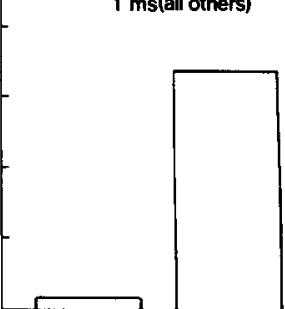

Figure 7. Top, Histograms illustrating the relative percentages of all isolated units with infraorbital receptive fields that responded to vibrissa or guard hair deflection, gentle skin indentation, or a noxious mechanical stimulus (L.T., low threshold). Data from the intact ganglia are shown at left for each of the 4 categories, while data from ganglia ipsilateral to neonatal infraorbital nerve section are shown at right for each of the 4 categories. Bottom, Oscillographs and histograms illustrating the response properties and corresponding relative percentages of units with functionally distinct infraorbital vibrissa receptive fields. See text for description of mechanical stimuli applied to vibrissae for each of the 5 units shown. Stimuli were always applied for the duration of the trace, except for those used to demonstrate high-velocity sensitivity $(n-p)$. All of these units were isolated with glass electrodes. Their short-latency responses to infraorbital $(I O)$ and brain-stem subnucleus caudalis $(S p V)$ shocks, at 2 times threshold current, are also shown in $d$ and $e, h$ and $i, l$ and $m, q$ and $r$, and $v$ and $w$, respectively. Arrows denote the onset of shock artifacts. The histograms indicate an increased relative percentage of sampled units with high-velocity or noxious-biased receptive fields subsequent to neonatal infraorbital nerve damage. 
Rostrocaudal maxillary fields, however, were not reconstituted in a very orderly fashion in the dorsoventral axis of the ganglion. There were many instances where a rostral vibrissal afferent was recorded in close proximity to a caudal vibrissal afferent. This was observed when either glass or tungsten electrodes were used. However, if one considers just the first and last vibrissal afferents recorded in a given penetration, a topographic trend was apparent. These data are summarized in Table 1. This table contains the number of the vibrissa represented most dorsally and most ventrally in the ganglion for each of 26 penetrations spanning the entire mediolateral extent of the intact ganglion. Note that all rows of vibrissae $(\mathrm{A}-\mathrm{F})$ were sampled most dorsally, while only ventral row vibrissae $(\mathrm{C}-\mathrm{F})$ were represented most ventrally. In 24 of 26 tracks containing at least 3 vibrissa-sensitive cells, the most dorsally recorded vibrissal afferent had a more caudal receptive field than that of the most ventrally recorded vibrissal afferent. Thus, an extremely rough topographic order exists within maxillary vibrissa-sensitive units in the dorsoventral axis of the ganglion. The existence of intradivisional order in the ganglion's dorsoventral axis is also supported by the distribution of intraoral maxillary units. They were recorded only in the ventral half of the ganglion.

\section{Axotomized side}

The data contained in Figures 4 and 6 suggest the following generalizations concerning the topographic organization of the ganglion ipsilateral to a neonatal infraorbital lesion:

1. Units with ophthalmic receptive fields were distributed throughout the ganglion's entire mediolateral dimension. Though occurring with greater frequency in its dorsal half, such units were often recorded in the ventral half of the ganglion.

2 . Units with mandibular receptive fields were distributed in a normal fashion (see point 2 above).

3 . Units with maxillary receptive fields were normally distributed (see point 3 above), spanning the entire mediolateral and dorsoventral axes of the ganglion.

4. An intradivisional topography was not readily apparent for maxillary units. Ganglion cells with nociceptive-biased receptive fields did not exhibit topographic order; widely divergent fields were frequently recorded from cells recorded at the same or adjacent loci. However, a comparison with intact ganglia is not warranted, since our sample of nociceptive-biased cells in intact ganglia was relatively small and did not permit topographic analysis. Concerning those cells that did respond to vibrissa(e) stimulation, profound topographic alterations were not observed. Dorsal and ventral row vibrissae were represented medially and laterally, respectively, with some ventral row vibrissal cells extending ventromedially. Moreover, oral sensitive units were recorded only ventrolaterally. However, as shown in Table 1, there did appear to be an absence of dorsoventral ganglionic topography for vibrissa(e)-sensitive units. In only 9 of 22 tracks did the most dorsally recorded vibrissal afferent innervate a vibrissa that was caudal to that of the most ventrally recorded vibrissal afferent (as compared with 24 of 26 in intact ganglia).

\section{Peripheral receptor associations}

In normals, and on the intact side of nerve-sectioned animals, $73.5 \%$ of the recorded cells had infraorbital receptive fields. Of these, $77.2 \%$ responded to vibrissal stimulation, $12.0 \%$ responded best to guard hair stimulation, $4.5 \%$ to gentle skin indentation, and $6.3 \%$ to a strong pinch or deep pressure applied to nonvibrissal infraorbital regions. In stereotaxically matched penetrations in ganglia ipsilateral to a neonatal infraorbital lesion, only $40.6 \%$ of the cells had infraorbital receptive fields. Of these, only $37.7 \%$ responded to vibrissal stimulation, while the remainder responded best to guard hair deflection $(11.9 \%)$, gentle skin indentation $(10.8 \%)$, or a strong pinch or deep pres-

\begin{tabular}{|c|c|c|c|}
\hline \multicolumn{2}{|l|}{ Intact } & \multicolumn{2}{|l|}{ Axotomized } \\
\hline $\mathrm{B} 2, \mathrm{C} 4$ & D1, D2 & $\mathrm{E} 7, \mathrm{C} 7^{*}$ & $\mathrm{C} 4, \mathrm{C} 2 *$ \\
\hline $\mathrm{E} 3, \mathrm{E} 1 *$ & $\mathrm{E} 1, \mathrm{E} 7$ & $\mathrm{E} 2, \mathrm{D} 2 *$ & $\mathrm{D} 4, \mathrm{C}^{*}$ \\
\hline $\mathrm{E} 4, \mathrm{~F} 7$ & $\mathrm{C} 1, \mathrm{D} 7$ & D-E, D1 & D3, E5 \\
\hline $\mathrm{C} 1, \mathrm{~F} 6$ & B2, F11 & D5, $C 1^{*}$ & $\mathrm{~B} 2, \mathrm{D} 7$ \\
\hline C-D, E6 & $\mathrm{A} 1, \mathrm{C} 3$ & $\mathrm{~B} 1, \mathrm{~B} 1^{*}$ & $\mathrm{E} 1, \mathrm{Cl}^{*}$ \\
\hline $\mathrm{D} 2, \mathrm{~F} 7$ & F1, E2 & $\mathrm{D} 1, \mathrm{~B} 2$ & F3, F10 \\
\hline $\mathrm{E} 4, \Gamma 1 *$ & B1, E6 & $A-B, B-C^{*}$ & A4, E4* \\
\hline E2, E8 & $\mathrm{C} 3, \mathrm{D} 7$ & $\mathrm{Cl}, \mathrm{El}^{*}$ & D4, D5 \\
\hline $\mathrm{B}-\mathrm{C}, \mathrm{F} 11$ & B1, D6 & A4, D4* & C3, E8 \\
\hline D1, D3 & $\mathrm{A} 1, \mathrm{C} 7$ & $\mathrm{~A}-\mathrm{B}, \mathrm{Cl}$ & D6, F1* \\
\hline D-E, F4 & A1, E6 & $\mathrm{A} 3, \mathrm{D} 3 *$ & D5, D7 \\
\hline $\mathrm{B}-\mathrm{C}, \mathrm{D} 7$ & C-D, E7 & & \\
\hline A-B, D6 & A-B, D7 & & \\
\hline \multicolumn{4}{|c|}{$\begin{array}{l}\text { In each electrode track, at least } 5 \text { units were isolated. Vibrissa nomenclature is } \\
\text { the same as that used by Zucker and Welker (1969): caudalmost vibrissae are } \\
\text { hyphenated; low numbers are caudal to higher numbers; A is most dorsal and F } F \text {, } \\
\text { is most ventral. *, Those electrode tracks where the most dorsally isolated cell's } \\
\text { receptive field was not caudal to that of the most ventrally isolated cell. Note that } \\
\text { this occurred in only } 2 \text { tracks through intact ganglia. However, in ganglia ipsilateral } \\
\text { to the lesion, this occurred in } 13 \text { of } 22 \text { tracks. }\end{array}$} \\
\hline
\end{tabular}

sure applied to nonvibrissal infraorbital regions (39.6\%). These comparisions are shown graphically in the top half of Figure 7. Thus, neonatal infraorbital nerve section resulted in a marked decrease in the relative percentage of cells that responded to vibrissal stimulation and an increase in the relative percentagc of cells that responded to noxious stimulation of nonvibrissal infraorbital regions. These changes were statistically reliable when relative percentages of receptive field types were compared across animals ( $t$ test, $p<0.05$ ).

The lower half of Figure 7 illustrates the response properties and relative numbers of functionally distinct vibrissa(e)-sensitive infraorbital units encountered in intact and lesioned cases. As shown in Figure 7, $a$ and $b$, slowly adapting type I vibrissal afferents responded with an irregular tonic discharge to deflection in either of 2 of the 4 orthogonal directions ( $c$ shows the absence of response to deflection in a nonpreferred direction). In intact ganglia, $43.8 \%$ of the infraorbital vibrissa-sensitive cells were slowly adapting type I, compared with only $29.8 \%$ in nerve-damaged animals. Figure $7, f-i$, shows the firing pattern of a typical slowly adapting type II vibrissal afferent. Note the highly regular tonic discharge. In intact ganglia, $10.3 \%$ of the infraorbital vibrissal cells responded in such a manner, while only $1.2 \%$ did so in lesioned cases. Figure $7, j-m$, illustrates the response properties of a typical low-velocity-sensitive, rapidly adapting vibrissal afferent. Note the presence of phasic "on" and "off" discharges to sustained deflection in either of 2 opposite directions. In intact ganglia, $27.6 \%$ of the infraorbital vibrissal cells were low-velocity-sensitive, while only $2.2 \%$ of the cells in nerve-sectioned animals responded as such. Figure $7, n-r$, describes the firing pattern of a representative highvelocity-sensitive, rapidly adapting vibrissal afferent. It responded in a transient manner to a rapid "flick" of a vibrissa in any direction $(n, o)$ but not to a slow displacement $(p)$. In intact ganglia, $16.8 \%$ of the infraorbital vibrissal cells had this type of receptive field, while $32.9 \%$ behaved similarly in lesioned subjects. Figure $7, s-w$, shows the responses of a vibrissal afferent to a noxious pinch of its follicle $(s)$, pulling of the vibrissa $(t)$, strong pressure applied to the follicle $(u)$, or shocks to the infraorbital nerve $(v)$ or subnucleus caudalis $(w)$. Though this par- 

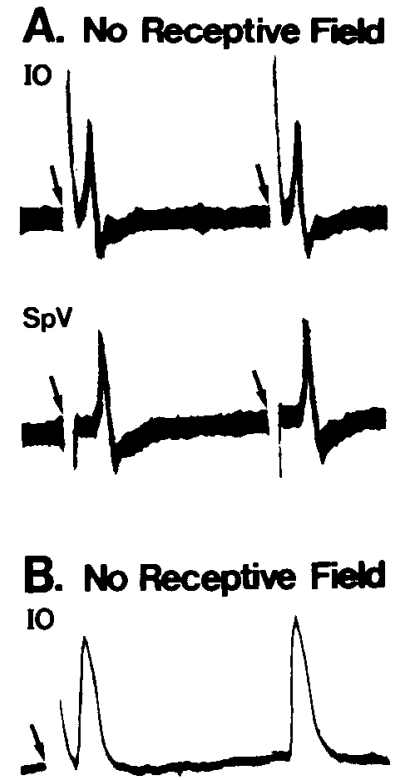

SpV
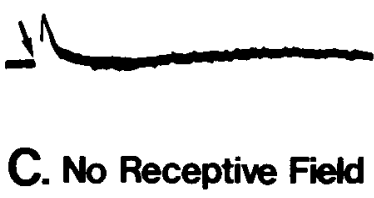

10

1
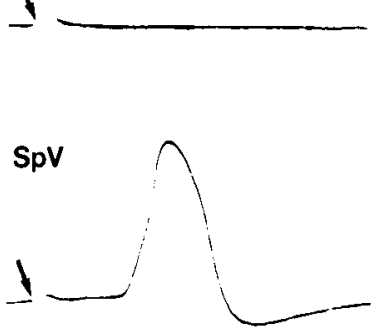
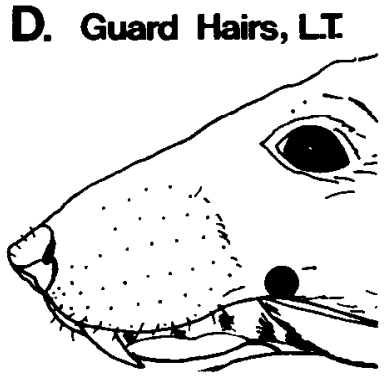

E. "Neuroma", Nox.

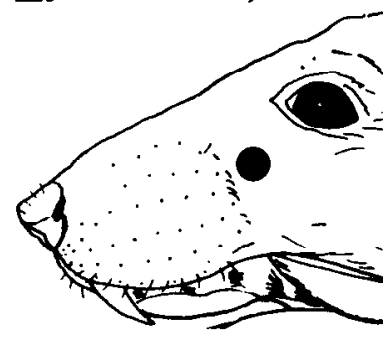

F. AI Vibrissa, L.T.

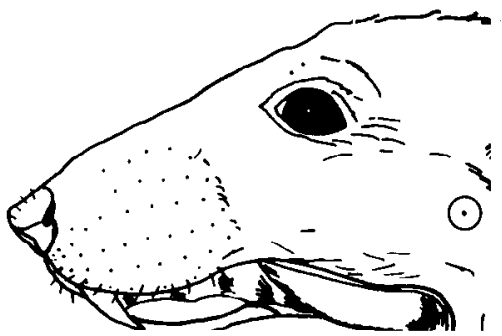

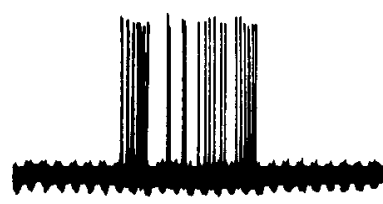

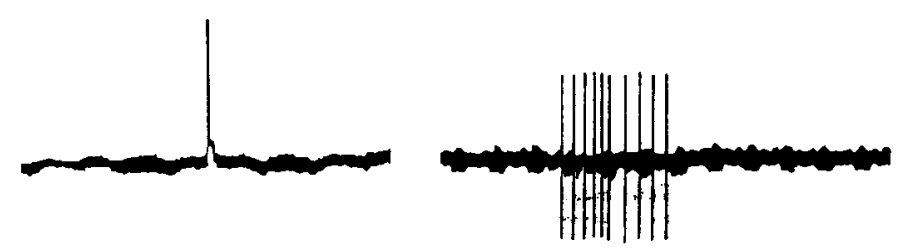

10

10
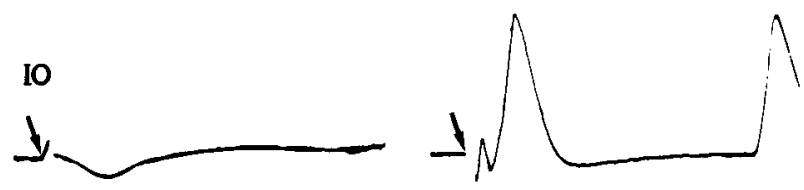

10
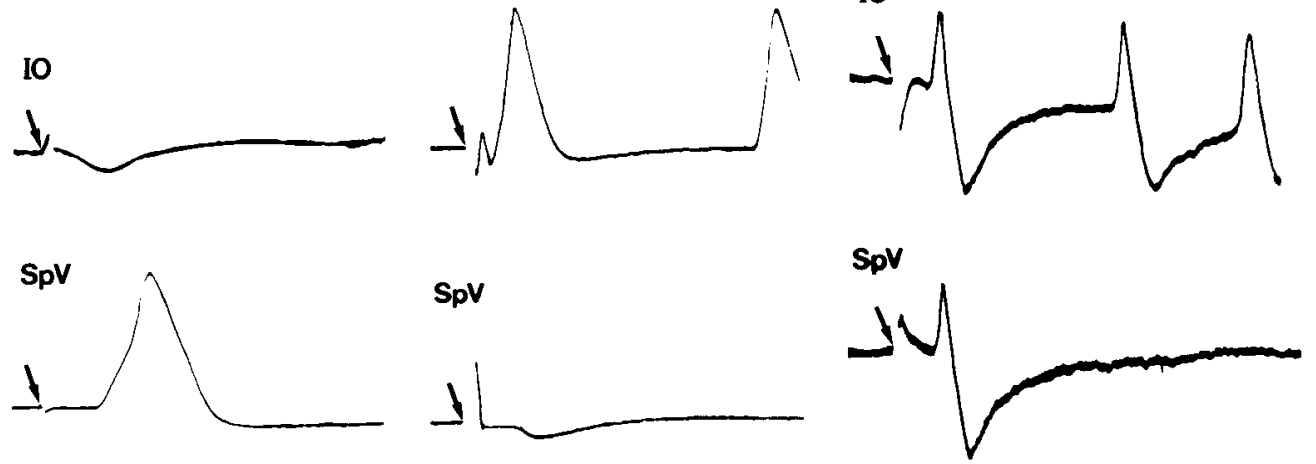

Figure 8. Examples of trigeminal ganglion cells with unusual peripheral and/or central projections subsequent to neonatal infraorbital nerve transection. $A-C$. Three cells without discernible receptive fields that were driven by IO and SpV shocks $(A)$, by IO shocks only $(B)$, or by SpV shocks only $(C) . D$. This cell responded phasically to infraorbital guard hair deflection yet was not driven by IO shocks. $E$, This unit responded phasically to deep pressure applied to the region of the nerve transection and to IO shocks yet did not discharge to SpV shocks. $F$, This cell was driven by both $\mathrm{IO}$ and $\mathrm{SpV}$ shocks, though it had a mandibular receptive field (circled auriculotemporal vibrissa). Arrows denote shock artifacts. All units isolated with glass electrodes.

ticular unit exhibited a tonic response to sustained noxious stimuli, some cells in this category responded with a phasic discharge. In intact ganglia, only $1.5 \%$ of the infraorbital vibrissal cells responded in a such manner, while $33.9 \%$ did so in nervedamaged cases. Thus, neonatal infraorbital nerve section resulted in a significantly higher percentage of velocity- or noxious-biased vibrissa-sensitive cells. These changes were statistically reliable.

The relative percentages of receptive field types for noninfraorbital cells was statistically unchanged in ganglia ipsilateral to the lesion.

\section{Peripheral and central projections}

In intact ganglia, all cells responded to, and followed high-frequency stimulation $(>200 \mathrm{~Hz}$ ) of, brain stem subnucleus caudalis. All cells with infraorbital receptive fields responded to stimulation of the infraorbital nerve. Moreover, each had a clearly defined receptive field that included 1 , and only 1 , of the following structures: a vibrissa, a group of guard hairs, hairy skin, glabrous skin, oral mucosa, nasal mucosa, a tooth, cornea, or a deep muscular or bony region. Adequate stimuli included 1 of the following: gentle indentation, slow deflection, rapid deflection, noxious pinch, or noxious pressure.

In ganglia ipsilateral to a neonatal lesion, we frequently observed cells with altered peripheral or central projections. Thirty cells did not have a detectable receptive field and were identified only by electric shocks to the infraorbital nerve and/or brain stem. Most (26) of these were driven by both of these stimulating electrodes (Fig. $8 A$ ), while 2 were not activated from the caudalis (Fig. $8 B$ ), and 2 were not driven from the infraorbital nerve (Fig. 8C). Seven cells with infraorbital receptive fields were not driven by infraorbital shocks (Fig. $8 D$ ), and 2 were not activated by brain-stem shocks (Fig. $8 E$ ). Three cells were driven by the infraorbital nerve yet had mandibular receptive fields (Fig. $8 F$ ). 
Thus, a neonatal infraorbital lesion resulted in altered peripheral projections in axotomized and nonaxotomized cells, and in altered central projections in axotomized cells.

Further evidence indicating altered peripheral projections of axotomized infraorbital cells was provided by a careful analysis of their receptive fields. In our sample, 9 units responded to more than 1 vibrissa, whereas in intact ganglia, each vibrissasensitive cell responded to only 1 vibrissa. The example shown in Figure $9 A$ responded in a rapidly adapting fashion to highvelocity deflection of the E5 (Fig. 9Aa) or E6 (Fig. 9Ab) vibrissae. The unit did not discharge when only the intervening guard hairs were displaced (Fig. 9AC). As can be seen in Figure 9, $A d$ and $A e$, this cell's axon projected through the infraorbital nerve and to the region of brain stem subnucleus caudalis. An additional level of complication in the peripheral connections of some vibrissa-sensitive infraorbital axons is illustrated in Figure $9 B$. In addition to responding in a phasic fashion to rapid deflection of more than 1 vibrissae (C1 and $\mathrm{C} 3$ vibrissae: Fig. 9, $B a, B b$ ), this cell also responded in a highly regular slowly adapting fashion to either pinching of the follicles of these vibrissae (Fig. $9 B c$ ) or tugging on the vibrissae (Fig. 9Bd). This cell therefore responded in a manner typical of CNS neurons that have been characterized as "wide dynamic range" (Price et al., 1976; Renehan et al., 1986). Four other cells responded to both vibrissa deflection (Fig. $9 \mathrm{Ca}$ ) and adjacent guard hair deflection (Fig. $9 \mathrm{Cb}$ ) but not to an adjacent vibrissa (Fig. $9 \mathrm{Cc}$ ).

Ten additional cells had unusually large, continuous receptive fields, often encompassing the entire infraorbital field. The unit illustrated in Figure $9 D$ responded in a rapidly adapting fashion to high-velocity deflection of the D5 vibrissa (Fig. 9Da) and in a slowly adapting manner to noxious stimulation of the D5 vibrissa follicle (Fig. 9Db). While a response could not be elicited by low-threshold stimulation of other vibrissae, noxious stimuli applied to the follicles of any of the E, D, or C row vibrissae evoked a tonic response (Fig. $9 D c$ ). In addition, sustained deflection of intervening guard hairs or hairy skin produced phasic (Fig. 9Dd) and tonic (Fig. 9De) discharges, respectively. One other "wide field" cell is described in Figure $9 F$. It responded in a phasic manner only to deep pressure applied to all regions of the vibrissae pad and rhinarium.

One cell exhibited a discontinuous, noxious receptive field (Fig. 9E). A rapidly adapting response was evoked by deep pressure applied to the caudal (Fig. 9Ea) and rostral (Fig. 9Eb) vibrissae pad but not by a similar stimulus applied to intervening regions (Fig. 9Ec).

Finally, 7 cells were recorded that responded only to deep pressure applied to the region of the intraorbital foramen. One example from this category is illustrated in Figure $9 G$. It responded in a phasic manner (Fig. $9 G a$ ) to noxious pressure delivered to the region shown in the line drawing but not to gentle skin indentation (Fig. $9 G b$ ) or hair deflection in overlying areas. Since such units were not encountered in intact ganglia, and because this area approximates the region in which the neonatal transaction was achieved, we interpret these receptive fields as being neuroma-related.

\section{Discussion}

The data described lead us to conclude that neonatal infraorbital nerve section results in (1) a significant loss of trigeminal ganglion cells that contribute axons to the infraorbital nerve; (2) altered intra- and interdivisional ganglionic topography; (3) altered peripheral receptor associations resulting in a significantly higher percentage of velocity- or noxious-biased infraorbital ganglion cells; (4) cells that do not have receptive fields yet maintain a projection into the infraorbital nerve; (5) cells that have infraorbital receptive fields yet lack an axon in the infraorbital nerve; (6) cells that have mandibular receptive fields and an axon in the infraorbital nerve; and (7) cells with unusual infraorbital receptive fields. Each of these issues will be discussed separately below with the limitations associated with each conclusion.

\section{Neonatal infraorbital nerve section kills ganglion cells}

In the present study we observed substantial shrinkage in the ophthalmic-maxillary portion of the trigeminal ganglion following neonatal infraorbital nerve section. Moreover, while cells were recorded with equivalent frequency in both nerve-damaged and intact cases, the percentage of recorded cells with infraorbital receptive fields decreased from 73.5 to $40.6 \%$. Since all trigeminal ganglion cells are born prenatally (Davies and Lumsden, 1984), these data indicate that neonatal axotomy adds substantially to the numbers of cells that die postnatally. This observation is qualitatively and quantitatively consistent with prior anatomical reports on neonatal nerve lesions. For example, Aldskogious and Risling (1981) have shown that sciatic nerve section in kittens results in a 33-49\% reduction in the number of neurons in the ipsilateral L-7 dorsal root ganglion. Risling et al. (1983) observed slightly less dramatic changes when this nerve was crushed rather than cut. In the trigeminal system, Savy et al. (1981) showed that vibrissae follicle cauterizations in neonatal mice produced a $30-40 \%$ decrement in the number of neurons in the ophthalmic-maxillary portion of the trigeminal ganglion. Waite (1984) demonstrated further that section of this nerve in newborn rats resulted in a $40-60 \%$ reduction in the number of myelinated axons in the nerve when the animals reached maturity. Retrograde tracing studies (Jacquin and Rhoades, 1983; B. G. Klein, W. E. Renehan, M. F. Jacquin, and R. W. Rhoades, unpublished observations) from the infraorbital nerve have also documented a large decrease in the number of ganglion cells giving rise to the infraorbital nerve subsequent to a neonatal transection. Moreover, preliminary electron-microscopic data (Mooney et al., 1983) suggest a similar reduction in both myelinated and unmyelinated axons comprising the infraorbital nerve following such a lesion.

\section{Neonatal infraorbital nerve section alters the topography of surviving ganglion cells}

We have used extracellular recording techniques to evaluate ganglionic topography. Our data may, however, be confounded by the intermingling of axons and cell bodies in the ganglion and the likelihood that many of our recordings were from axons. This is problematic if axonal and somal topography differ. We have attempted to resolve this problem by comparing the locations of somata and axons for an admittedly small sample of individual ganglion cells. Intracellularly labeled somata and axons maintained closely apposed locations in the dorsoventral and mediolateral axes for all of our recovered neurons. Since these are the only 2 dimensions in which order was exhibited in intact ganglia, and in which a denervation effect was observed, our analysis should be a valid one.

Mandibular and oral maxillary units maintained their normal topographic positions in nerve-damaged animals, while ophthalmic and infraorbital cells exhibited altered topography. It seems likely that the "spread" of ophthalmic cells into lateral and ventral portions of the ganglion reflects the death of infraorbital cells that ordinarily would occupy more lateral and ventral areas. Their deletion may have simply redefined ganglionic borders and the relative positioning of ophthalmic cells. However, the absence of any sign of dorsoventral topography for infraorbital units is probably due to errors in the peripheral projections of regenerate axons. As stated in the introduction, these topographic errors may be passed on without further change to the remainder of the trigeminal neuraxis, thereby contributing to the altered maps that have been described in the brain stem, thalamus, and cortex following a similar lesion. Additional experiments are in progress to determine whether these topograph- 
A. 2 Vibrissae, L.T.

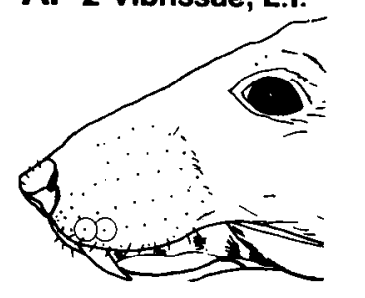

a

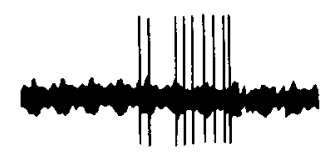

b

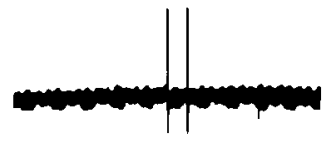

c
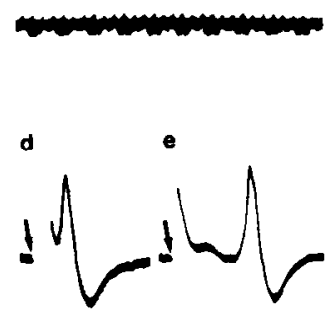

B. 3 Vibrissae,

\section{L.T. \& Nox.}

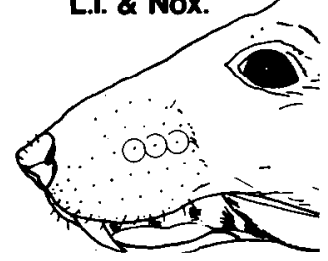

a

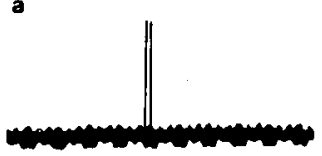

b

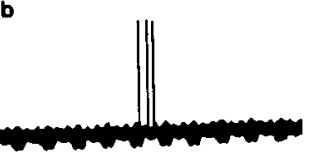

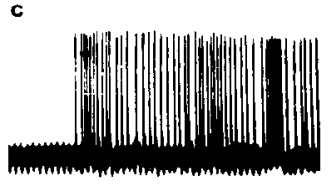

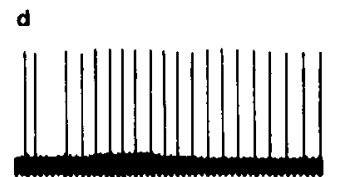

e

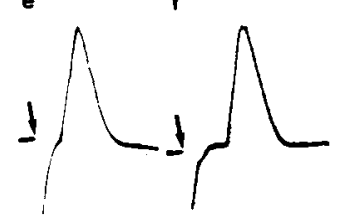

D. Several Vibrissae, G.H. \& Skin,
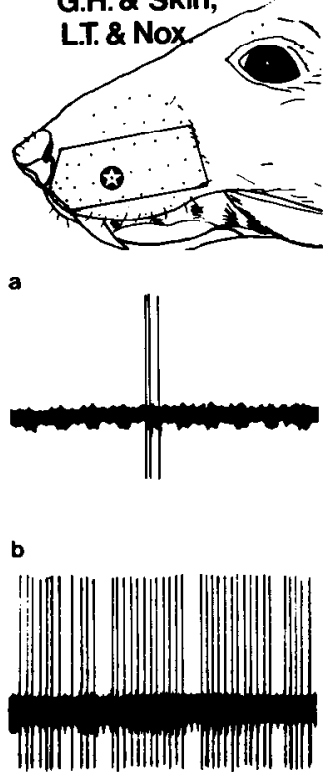

b

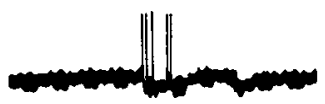

E. Split Field, Nox.

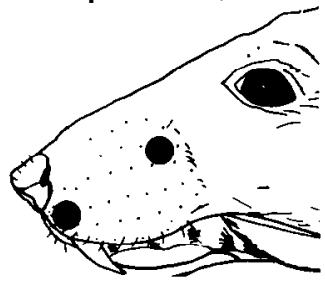

a

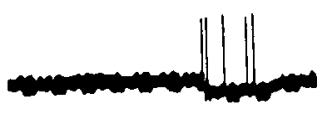

F. Wide Field, Nox.

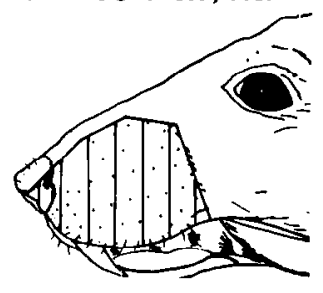

a
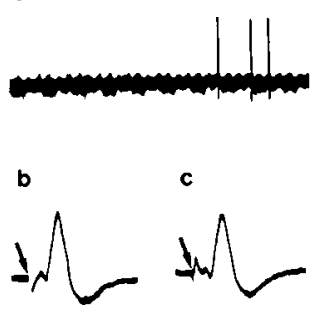

C. 1 Vibrissa \& G.H.,

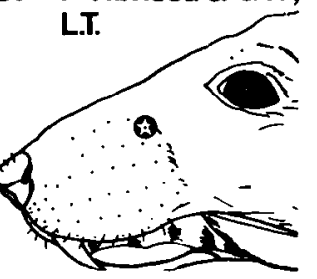

c
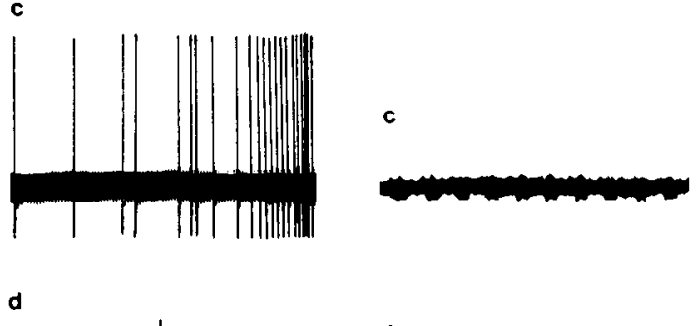

G. "Neuroma", Nox.

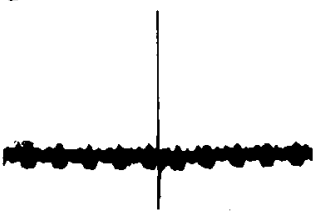

d

e
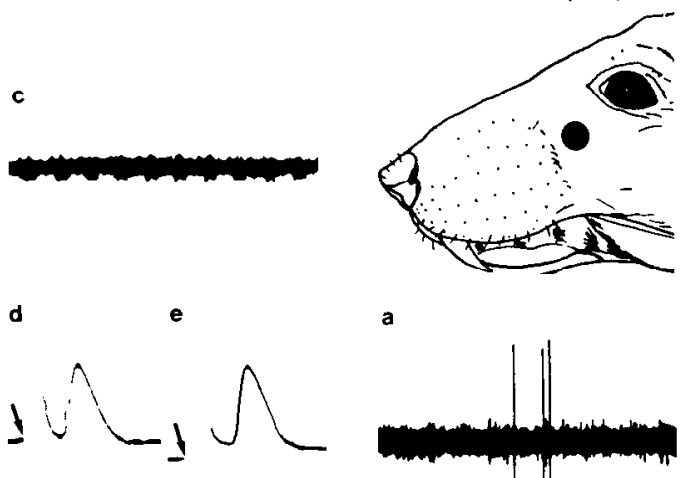

a

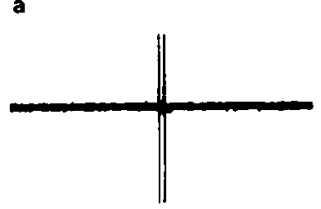

b

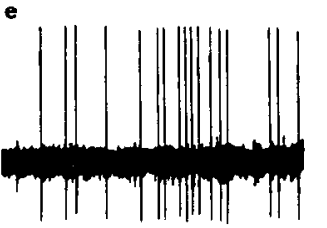

10 mv(others)

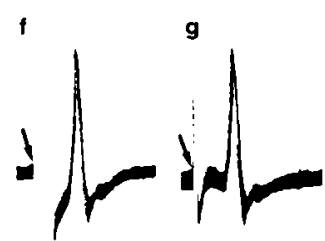

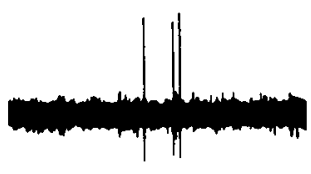

b

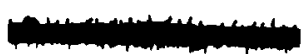

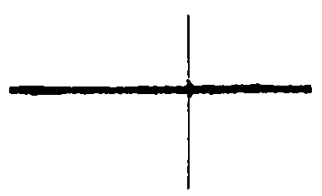

c

$0.5 \mathrm{~ms}(\mathrm{Ad}+\mathrm{e}, \mathrm{Be}+\mathrm{f}, \mathrm{Ed}+\mathrm{e})$ $1.0 \mathrm{~ms}(\mathrm{Df}+\mathrm{g}, \mathrm{Fb}+\mathrm{C}, \mathrm{GC}+\mathrm{d})$ $200 \mathrm{~ms}(\mathrm{BC}+\mathrm{d}, \mathrm{Ca}-\mathrm{c}, \mathrm{Db}-\mathrm{e})$ $50 \mathrm{~ms}$ (all others)

Figure 9. Examples of unusual receptive fields in neonatally axotomized trigeminal ganglion cells. When cells were isolated with glass electrodes, responses to $\mathrm{IO}$ and $\mathrm{SpV}$ shocks are also shown, respectively. Receptive fields are indicated on the line drawings. See text for explanation of stimuli applied in each trace.

ic alterations are maintained by the central brain-stem arbors of denervated ganglion cells.

It should also be noted that our map of the intact ganglion is consistent with that obtained by others using anatomical and physiological techniques (see Jacquin et al., 1983, for a review).
Neonatal infraorbital nerve section alters the distribution of peripheral receptor associations

Our data indicate that a neonatal infraorbital lesion results in a significantly higher percentage of velocity- or noxious-biased 
infraorbital cells. This result may, however, be confounded by sensitization. A number of authors (e.g., Beitel and Dubner, 1976; Geisler et al., 1979) have noted that repeated testing with noxious stimuli can alter the responsivity of somatosensory neurons. We have tested the possibility that this might have affected our results in 2 ways. First, the response properties of a large number of ganglion cells were retested after multiple applications of a noxious pinch with serrated forceps. These tests never revealed any shifts in the responses of these cells. Second, we compared the data collected at the beginning of a given recording experiment with those obtained just prior to termination. Again, there was no indication that sensitization affected the receptive field characteristics of our sample.

Clinical studies in humans have consistently documented diminished sensory function in skin supplied by a regenerate nerve (e.g., Hallin et al., 1981; Hawkins, 1948; Mackel et al., 1983, 1985; Onne, 1962). Surprisingly, however, single-unit recordings from human regenerate nerve fibers have revealed only subtle changes in the receptive fields of individual axons. Hallin et al. (1981) reported a few fibers with multiple disparate receptive fields, while the findings of Mackel et al. (1983, 1985) suggest that Pacinian corpuscles might not be reinnervated by regenerating fibers of the median or ulnar nerves. One may conclude, based upon these electrophysiological studies, that regenerate axons reclaim their original territories and elaborate similar receptor associations. A review of the animal literature also supports this conclusion and indicates further that axons of a given type generally make contact with their appropriate receptors upon regeneration. For example. Devor et al. (1979) have shown that the crushed sciatic nerve regenerates into its normal peripheral territory and displaces saphenous nerve sprouts from this region. Horch and his colleagues (e.g., Burgess et al., 1974; Horch, 1979) have reported similar results for the femoral cutancous ncrve in adult cats. These and other experiments (Dykes and Terzis, 1979; Terzis and Dykes, 1980; Turnbull, 1982) have also indicated that regenerating axons reform normal receptor associations. However, Burgess and Horch (1973) have shown that regenerate type I fibers could be activatcd both from touch domes and surrounding skin. This observation is consistent with our finding of single axons forming multiple, different receptor associations.

In the trigeminal system, several studies have demonstrated that severed trigeminal nerves will reinnervate their normal peripheral territories upon regeneration. Robinson (1981), for example, has shown that the inferior alveolar nerve will reinnervate the appropriate teeth, mucosa, and skin following adult transection in cat. The receptive fields also appeared normal in these animals. However, we know of no study that has examined peripheral reinnervation after neonatal damage to sensory axons. Our results suggest that regenerate peripheral receptor associations are dramatically altered by neonatal infraorbital nerve transection. Indeed, we found that velocity- or noxious-biased units were disproportionately overrepresented subsequent to this lesion. This most likely reflects a failure to reform a normal tactile receptor, particularly with respect to the vibrissae. This receptor organ is well known to receive an elaborate array of cutaneous receptors (Andres, 1966; Patrizzi and Munger, 1966; Renehan and Munger, 1986), some of which are permanently altered by adult infraorbital nerve section (Renehan and Munger, 1986b). Given the response properties of the majority of infraorbital cells ipsilateral to a neonatal lesion, we would predict that a similar set of morphological anomalies exists for regenerate axons in the periphery of the neonatally nerve-damaged rat.

On the other hand, the altered distribution of receptive field types could reflect a disproportionately high rate of survival of axotomized noxious- and velocity-biased cells as a result of their relative success in reforming peripheral connections. Slowly adapting and low-velocity-biased cells may not be as successful in elaborating their preoperative receptor status and therefore die. Thus, an alternative hypothesis is that surviving cells do form accurate receptor associations; however, the observed altered distribution of receptor types reflects functionally selective cell death. A reasonable prediction consistent with this hypothesis is that the surviving ganglion cells would have smaller somal diameters since primary afferent nociceptors are thought to have smaller cell bodies. A recent retrograde tracing study (B. G. Klein, W. E. Renehan, M. F. Jacquin, and R. W. Rhoades, unpublished observations), however, indicates that neonatal infraorbital nerve section does not alter the average somal dianleter or cell size distribution in surviving infraurbilal ganglion cells. These data therefore argue against the functionally selective cell death hypothesis.

An additional interpretation of these data is that the neonatal lesion spared fibers that had not yet extended from the ganglion through the region of the transection. Recent experiments by Rice and Munger (1986) have documented sequential waves of receptor differentiation in the rat vibrissae pad, with vibrissae the first to be innervated prenatally, followed by postnatal guard hair and hairy skin innervation. If we assume that the postnatally differentiating fibers were spared and managed to traverse the region of the transection, then it should follow that guard hair and hairy skin axons would be disproportionately overrepresented subsequent to a lesion. This was not the case.

Another attractive prediction is that the central projections of rcgencratc infraorbital axons would be disproportionately overrepresented in regions of the brain stem known to process injurious stimuli, such as laminae I and II in the subnucleus caudalis (Jacquin et al., 1986; Renehan et al., 1986). Our initial experiments (Jacquin and Rhoades, 1983) using transganglionic HRP transport from the regenerate infraorbital nerve did, in fact, show that this region was heavily labeled, while other laminae and subnuclei contained only sparse label. This would suggest either that some cells fail to maintain their central projections or that cells processing nonnociceptive information reroute their axons to innervate primarily laminae I and II of the caudalis. The latter possibility would appear more likely, given that only 2 cells in our sample were not driven by caudalis shocks. We are now examining the central projections of individual axons with altered peripheral projections to determine how the latter is transmitted to the CNS.

\section{Neonatal infraorbital nerve section alters the peripheral projections of trigeminal ganglion cells}

The following alterations were observed: 1 . Cells that do not have receptive fields yet maintain a projection through the infraorbital nerve. Twenty-eight cells could not be activated by a peripheral stimulus yet could be driven from the infraorbital nerve at a point proximal to the neonatal transection. This suggests that some cells maintain a peripheral axon without forming a functional receptor association. Some of these may not have regenerated subsequent to the lesion; others may have become embedded in a neuroma, though this does not necessarily preclude the formation of a receptive field (see below); while still others may have extended well into the vibrissal pad region. Peripheral intraaxonal labeling studies would be required to discern which of these possibilities is most likely following transection.

2. Cells that do not have receptive fields and lack a projection through the infraorbital nerve. While this was observed for only 2 cells, it suggests that a peripheral axon may degenerate without cell death or that the axon was rerouted through another peripheral nerve but failed to form a functional receptor.

3. Cells that have infraorbital receptive fields yet do not have 
an axon in the infraorbital nerve. This, of course, suggests the occurrence of lesion-induced peripheral sprouting from undamaged fibers. Jackson and Diamond (1984) have recently shown that axons innervating low-threshold mechanoreceptors will invade denervated peripheral territory in perinatal rats. This possibility has received only limited attention in the trigeminal system. Fitzgerald (1963) has concluded, on the basis of data obtained with silver-staining techniques, that adult unilateral infraorbital nerve section results in significant transmedial sprouting in fibers from the contralateral infraorbital nerve. Robinson (1983) has more recently reported behavioral observations which suggest that section of the trigeminal sensory root in humans also produces a significant increase in the transmedial innervation of the face. Robinson $(1981,1982)$ has also provided electrophysiological evidence that ipsilateral denervation of adult canine teeth produces sprouting into denervated tissues by fibers from the ipsilateral lingual and contralateral lingual and inferior alveolar nerves. However, to our knowledge, peripheral sprouting subsequent to a neonatal trigeminal nerve section has not been evaluated. The present results are consistent with this possibility, though we cannot rule out the presence of noninfraorbital afferents in the vibrissal pad region prior to nerve section that do not contribute to the receptive fields of noninfraorbital afferents. Anatomical studies are required to rule out this possibility and to determine which trigeminal branches sprout into denervated territory.

4. Cells that have mandibular receptive fields and an axon in the infraorbital nerve. The presence of ganglion cells with interdivisionally branching peripheral projections subsequent to a neonatal lesion could reflect either collateral sprouting (i.e., lesion-induced elaboration of a new axon branch) or the failure to retract of a normally transient axon collateral. Additional anatomical experiments have been carried out (Klein et al., 1986; Rhoades et al., 1987) which support the collateral sprouting hypothesis. The reader is referred to these papers for a discussion.

5. Cells with unusual infraorbital receptive fields. We have described a large number of receptive field types that do not normally exist for trigeminal ganglion cells. These include split low-threshold (multiple vibrissae) and nociceptive fields and continuous low- and high-threshold fields that can incorporate multiple receptor types (vibrissal, guard hair, skin, and deep tissues), and nociceptive fields restricted to the region of the nerve section. The latter receptive field type we have referred to as neuroma-related. It is well known that severed axons can sometimes be activated by mechanical stimulation of the resultant neuroma (see Scadding, 1981; Wall and Devor, 1978, for reviews). Our results are consistent with this observation, though none of our neuroma-related cells was spontaneously active, as has been reported for dorsal root ganglion cells (e.g., Burchiel, 1984). This may represent a fundamental difference in the response of peripheral nerve to transection in infancy vs adulthood.

\section{Central correlates of peripheral nerve alterations}

The results of the present study bear upon current models of CNS map formation (e.g., Belford and Killackey, 1979; Durham and Woolsey, 1984; Erzurumlu and Killackey, 1983; Harris and Woolsey, 1981; Jeanmonod et al., 1981; Steffen and Van der Loos, 1981), which propose that development proceeds from the periphery to the cortex with afferent topography influencing cellular aggregation at the succeeding level. It has been hypothesized that peripheral nerve damage alters central connectivity either through loss of some primary afferent fibers (Belford and Killackey, 1979, Fig. 9; Jeanmonod et al., 1981, Fig. 8), or as a result of redistribution of trigeminal ganglion cells that innervate a given vibrissa follicle (Jeanmonod et al., 1981, Fig.
8 ), or through regeneration of individual axons into multiple follicles and/or skin (Jeanmonod et al., 1981; Simons et al., 1984). To date, however, information concerning the peripheral projections of axotomized ganglion cells has been limited. Our data indicate that all of these hypothesized events occur following neonatal infraorbital nerve section, thus providing a basis for interpreting the functional changes that occur in the somatosensory cortical barrel field following neonatal peripheral lesions. For example, it has been shown that cortical cells that normally respond to 1 vibrissa (Simons, 1978; Welker, 1971; Welker and Woolsey, 1974; but see Ito, 1981, for contradictory data) become responsive to multiple vibrissae and surrounding skin (Killackey et al., 1978; Pidoux et al., 1979; Simons et al., 1984; Waite and Taylor, 1978; Welt, 1977). Such changes must at least partially reflect the changes in peripheral connectivity we have described. This, of course, does not preclude additional contributions made by alterations in the central arbors of lesioned ganglion cells or anatomical and physiological alterations that might be observed in second- and third-order trigeminal neurons (see Waite, 1984, for additional discussion).

\section{References}

Aldskogious, H., and M. Risling (1981) Effects of sciatic neurectomy on number and size distribution in the L-7 ganglion of kittens. Exp. Neurol. 74: 597-604.

Andres, K. H. (1966) Uber die Feinstruktur der Rezeptoren an Sinushaaren. Z. Zellforsch. 75: 339-365.

Bates, C. A., and H. P. Killackey (1985) The organization of the nconatal rat's brainstem trigcminal complex and its role in the formation of central trigeminal patterns. J. Comp. Neurol. 240: 265287.

Beitel, R. E., and R. Dubner (1976) Response of unmyelinated (C) polymodal nociceptors to thermal stimuli applied to the monkey's face. J. Neurophysiol. 39: 1160-1175.

Belford, G. R., and H. P. Killackey (1979) Vibrissae representation in subcortical trigeminal centers of the neonatal rat. J. Comp. Neurol. 183: 305-322.

Belford, G. R., and H. P. Killackey (1980) The sensitive period in the development of the trigeminal system. J. Comp. Neurol. 193: 335350.

Brown, A. G., and A. Iggo (1967) A quantitative study of cutaneous receptors and afferent fibres in the cat and rabbit. J. Physiol. (Lond.) 193: 707-733.

Burchiel, K. J. (1984) Effects of electrical and mechanical stimulation on two foci of spontaneous activity which develop in primary afferent neurons after peripheral axotomy. Pain 18: 249-265.

Burgess, P. R., and K. W. Horch (1973) Specific regeneration of cutaneous fibers in the cat. J. Neurophysiol. 36: 101-114.

Burgess, P. R., and E. R. Perl (1973) Cutaneous mechanoreceptors and nociceptors. In Handbook of Sensory Physiology, Vol. 2: Somatosensory System, A. Iggo, ed., pp. 29-78, Springer-Verlag, Heidelberg.

Burgess, P. R., K. B. English, K. W. Horch, and L. J. Stensaas (1974) Patterning in the regeneration of type I cutaneous mechanoreceptors. J. Physiol. (Lond.) 236: 57-82.

Davies, A., and A. Lumsden (1984) Relation of target encounter and neuronal death to nerve growth factor responsiveness in the developing mouse trigeminal ganglion. J. Comp. Neurol. 223: 124-137.

Devor, M., D. Schoenfeld, Z. Seltzer, and P. D. Wall (1979) Two modes of culaneous reinnervation following peripheral nerve injury. J. Comp. Neurol. 185: 211-220.

Durham, D., and T. A. Woolsey (1984) Effects of neonatal whisker lesions on mouse central trigeminal pathways. J. Comp. Neurol. 223: 424-447.

Dykes, R. W., and J. K. Terzis (1979) Reinnervation of glabrous skin in baboons: Properties of cutaneous mechanoreceptors subsequent to nerve crush. J. Neurophysiol. 42: 1461-1478.

Erzurumlu, R. S., and H. P. Killackey (1983) Development of order in the rat trigeminal system. J. Comp. Neurol. 213: 365-380.

Fitzgerald, M. J. T. (1963) Transmedian cutaneous innervation. J. Anat. 97: 313-322.

Geisler, G. G., U. Gideon, J. T. Cannon, and J. C. Liebeskind (1979) 
Response properties of neurons of the lateral cervical nucleus in the rat. J. Comp. Neurol. 186: 65-77.

Gottschaldt, K.-M., A. Iggo, and D. W. Young (1973) Functional characteristics of mechanoreceptors in sinus hair follicles of the cat. J. Physiol. (Lond.) 235: 287-315.

Hallin, R. G., Z. Wiesenfeld, and U. Lindblom (1981) Neurophysiological studies on patients with sutured median nerves: Faulty sensory localization after nerve regeneration and its physiological correlates. Exp. Neurol. 73: 90-106.

Harris, R. M., and T. A. Woolsey (1981) Dendritic plasticity in mouse barrel cortex following postnatal vibrissa follicle damage. J. Comp. Neurol. 196: 357-376.

Hawkins, G. L. (1948) Faulty sensory localization in nerve regeneration. An index of functional recovery following suture. J. Neurosurg. 5: $11-18$

Horch, K. (1979) Guidance of regrowing sensory axons after cutaneous nerve lesions in the cat. J. Neurophysiol. 42: 1437-1449.

Ito, M. (1981) Some quantitative aspects of vibrissa-driven neuronal responses in rat neocortex. J. Neurophysiol. 46: 705-715.

Jackson, P. C., and J. Diamond (1984) Temporal and spatial constraints on the collateral sprouting of low threshold mechanosensory nerves in the skin of rats. J. Comp. Neurol. 226: 336-345.

Jacquin, M. F., and R. W. Rhoades (1983) Central projections of the normal and "regenerate" infraorbital nerve in adult rats subjected to neonatal unilateral infraorbital lesions: A transganglionic horseradish peroxidase study. Brain Res. 269: 137-144.

Jacquin, M. F., and R. W. Rhoades (1985) Effects of neonatal infraorbital lesions upon central trigeminal primary afferent projections in rat and hamster. J. Comp. Neurol. 235: 129-143.

Jacquin, M. F., and R. W. Rhoades (1986) Development and plasticity in hamster trigeminal primary afferent projections. Dev. Brain Res. (in press)

Jacquin, M. F., K. Semba, M. D. Egger, and R. W. Rhoades (1983) Organization of HRP-labeled trigeminal mandibular primary afferent neurons in the rat. J. Comp. Neurol. 215: 397-420.

Jacquin, M. F., R. D. Mooney, and R. W. Rhoades (1984) Acute changes in superior collicular somatosensory receptive fields following infraorbital nerve section and peripheral xylocaine injection. J. Physiol. (Lond.) 348: 471-492.

Jacquin, M. F., W. E. Renehan, R. D. Mooney, and R. W. Rhoades (1986) Structure-function relationships in rat medullary and cervical dorsal horns. I. Trigeminal primary afferents. J. Neurophysiol. 55: $1153-1186$

Jeanmonod, D., F. L. Rice, and H. Van der Loos (1981) Mouse somatosensory cortex: Alterations in the barrelfield following receptor injury at different early postnatal ages. Neuroscience 6: 1503-1535.

Killackey, H. P., G. Belford, R. Ryugo, and D. K. Ryugo (1976) Anomalous organization of thalamocortical projections consequent to vibrissae removal in the newborn rat and mouse. Brain Res. 104: 309315 .

Killackey, H. P., G. O. Ivy, and T. J. Cunningham (1978) Anomalous organization of SmI somatotopic map consequent to vibrissae removal in the newborn rat. Brain Res. 155: 136-140.

Klein, B. G., G. Macdonald, A. M. Szczepanik, and R. W. Rhoades (1986) Topographic organization of peripheral trigeminal ganglionic projections in newborn rats. Dev. Brain Res. 27: 257-262.

Mackel, R., E. Kunesch, F. Waldhor, and A. Struppler (1983) Reinnervation of mechanoreceptors in the human glabrous skin following peripheral nerve repair. Brain Res. 268: 49-65.

Mackel, R., E. E. Brink, and G. Wittkowsky (1985) Properties of cutaneous mechanosensitive afferents during the early stages of regeneration in man. Brain Res. 329: 49-69.

Math, M., B. G. Klein, and R. W. Rhoades (1984) Topographic representation of vibrissae follicles in the trigeminal ganglion of normal adult rats and adults subjected to neonatal transection of infraorbital nerve. Soc. Neurosci. Abstr. 10:1156.

Mooney, R. D., A. Hess, M. F. Jacquin, and R. W. Rhoades (1983) An electron microscopic analysis of the infraorbital nerve in rat. Soc. Neurosci. Abstr. 9: 781.

Onne, L. (1962) Recovery of sensibility and sudomotor activity in the hand after nerve suture. Acta Chirurg. Scand. [Suppl.] 300: 1-69.

Patrizzi, G., and B. Munger (1966) The ultrastructure and innervation of rat vibrissae. J. Comp. Neurol. 126: 423-436.

Pidoux, B., R. Verley, E. Farkas, and J. Scherrer (1979) Projections of the common fur of the muzzle upon the cortical area for mystacial vibrissae in rats dewhiskered since birth. Neurosci. Lett. 11: 301306.

Price, D. D., R. Dubner, and J. Hu (1976) Trigeminothalamic neurons in the nucleus caudalis responsive to tactilc, thermal and nociceptive stimulation of the monkey's face. J. Neurophysiol. 39: 936-953.

Renehan, W. E., and B. L. Munger (1986a) Degeneration and regeneration of peripheral nerve in the rat trigeminal system. I. Identification and characterization of the multiple afferent innervation of the mystacial vibrissae. J. Comp. Neurol. 246: 129-146.

Renehan, W. E., and B. L. Munger. (1986b) Degeneration and regeneration of peripheral nerve in the rat trigeminal system. II. Reinnervation of the mystacial vibrissae. J. Comp. Neurol. (in press).

Renehan, W. E., M. F. Jacquin, B. G. Klein, R. D. Mooney, and R. W. Rhoades (1985) Response properties of trigeminal ganglion cells in adult rats with neonatal infraorbital nerve sections. Anat. Rec. 211: 159A.

Renehan, W. E., M. F. Jacquin, R. D. Mooney, and R. W. Rhoades (1986) Structure-function rclationships in rat medullary and cervical dorsal horns. II. Medullary dorsal horn cells. J. Neurophysiol. 55: 1187-1201.

Rhoades, R. W., J. Fiore, M. Math, and M. F. Jacquin (1983a) Reorganization of trigeminal primary afferents following neonatal infraorbital nerve section in hamster. Dev. Brain Res. 7: 337-342.

Rhoades, R. W., R. D. Mooney, and M. F. Jacquin (1983b) Complex somatosensory receptive fields of cells in the deep laminae of the hamster's superior colliculus. J. Neurosci. 3: 1342-1354.

Rhoades, R. W., N. L. Chiaia, R. D. Mooney, B. G. Klein, W. E. Renehan, and M. F. Jacquin (1987) Reorganization of the peripheral projections of the trigeminal ganglion following neonatal transection of the infraorbital nerve. Somatosens. Res. (in press).

Rice, F. L., and B. Munger (1986) Sequential maturation of cutaneous receptors in the rat mystacial pad. J. Comp. Neurol. (in press).

Risling, M., H. Aldskogious, C. Hildebrand, and S. Remahl (1983) Effects of sciatic nerve resection on L-7 spinal roots and dorsal root ganglia in adult cats. Exp. Neurol. 82: 568-580.

Robinson, P. P. (1981) Reinnervation of teeth, mucous membrane and skin following section of the inferior alveolar nerve in the cat. Brain Res. 220: 241-253.

Robinson, P. P. (1982) The persistence of collateral reinnervation of cat teeth in the presence of regenerated native nerve fibres. J. Physiol. (Lond.) 327: 30P.

Robinson, P. P. (1983) Recession of sensory loss from midline following trigeminal sensory root section: Collateral sprouting from the normal side? Brain Res. 259: 177-180.

Savy, C., S. Margules, E. Farkas-Bargeton, and R. Verley (1981) A morphometric study of mouse trigeminal ganglion after unilateral destruction of vibrissae follicles at birth. Brain Res. 217: 265-277.

Scadding, J. W. (1981) The development of ongoing activity, mechanosensitivity, and adrenaline sensitivity in severed peripheral nerve axons. Exp. Neurol. 73: 345-364.

Simons, D. J. (1978) Response properties of vibrissa units in the rat SI somatosensory neocortex. J. Neurophysiol. 41: 798-820.

Simons, D. J., D. Durham, and T. A. Woolsey (1984) Functional organization of mouse and rat SmI barrel cortex following vibrissal damage on different postnatal days. Somatosens. Res. 1: 207-245.

Steffen, H., and H. Van der Loos (1981) Early lesions of mouse vibrissal follicles: Their influence on dendritic orientation in the cortical barrel field. Exp. Brain Res. 40: 419-431.

Terzis, J. K., and R. W. Dykes (1980) Reinnervation of glabrous skin in baboons: Properties of cutaneous mechanoreceptors subsequent to nerve transection. J. Neurophysiol. 44: 1214-1225.

Turnbull, B. G. (1982) Cutaneous reinnervation following replantation or nerve transection and repair. M.Sc. Thesis, McGill University, Montreal.

Van der Loos, H., and T. A. Woolsey (1973) Somatosensory cortex: Structural alterations following early injury to sense organs. Science 179: 395-398.

Verley, R., and I. Onnen (1981) Somatotopic organization of the tactile thalamus in normal adult and developing mice and in adult mice dewhiskered since birth. Exp. Neurol. 72: 462-474.

Waite, P. M. E. (1984) Rearrangement of neuronal responses in the trigeminal system of the rat following peripheral nerve section. J. Physiol. (Lond.) 352: 425-445.

Waite, P. M. E., and B. G. Cragg (1979) The effect of destroying the whisker follicles in mice on the sensory nerve, the thalamocortical 
radiation and cortical barrel development. Proc. R. Soc. Lond. [Biol.] 204: 41-55.

Waite, P. M. E., and B. G. Cragg (1982) The peripheral and central changes resulting from cutting or crushing the afferent nerve supply to the whiskers. Proc. R. Soc. Lond. [Biol.] 214: 191-211.

Waite, P. M. E., and P. K. Taylor (1978) Removal of whiskers in young rats causes functional changes in cerebral cortex. Nature 274: 600-602.

Wall, P. D., and M. Devor (1978) Physiology of sensation after peripheral nerve injury, regeneration, and neuroma formation. In Physiology and Pathobiology of Axons, S. G. Waxman, ed., pp. 377-388, Raven, New York.

Welker, C. (1971) Microelectrode delineation of fine grain somatotopic organization of SmI cerebral neocortex in albino rat. Brain Res. 26: 259-275.

Welker, C., and T. A. Woolsey (1974) Structure of layer IV in the somatosensory neocortex of the rat: Description and comparison with the mouse. J. Comp. Neurol. 158: 437-454.
Weller, W. L., and J. I. Johnson (1975) Barrels in cerebral cortex altered by receptor disruption in newborn, but not in five-day-old mice (Cricitidae and Muridae). Brain Res. 83: 504-508.

Welt, C. (1977) Physiological organization of the rat cortical barrel field following neonatal vibrissal damage. Soc. Neurosci. Abstr. 3: 494.

Woolsey, T. A., and J. R. Wann (1976) Areal changes in mouse cortical barrels following vibrissal damage at different postnatal ages. J. Comp. Neurol. 170: 53-66.

Woolsey, T. A., J. R. Anderson, J. R. Wann, and B. B. Stanfield (1979) Effects of early vibrissal damage on neurons in the ventrobasal (VB) thalamus of the mouse. J. Comp. Neurol. 184: 363-380.

Zucker, E., and W. I. Welker (1969) Coding of somatic sensory input by vibrissae neurons in the rat's trigeminal ganglion. Brain Res. 12: 138-156. 